Published in final edited form as:

JMed Chem. 2018 February 22; 61(4): 1595-1608. doi:10.1021/acs.jmedchem.7b01710.

\title{
New Steroidal 4-Aminoquinolines Antagonize Botulinum Neurotoxin Serotype A in Mouse Embryonic Stem Cell Derived Motor Neurons in Post-intoxication Model
}

\author{
Jelena Konstantinović ${ }^{\prime}$, Erkan Kiris ${ }^{\ddagger}$, Krishna P. Kota ${ }^{\dagger}$, Johanny Kugelman Tonos ${ }^{\dagger}$, Milica

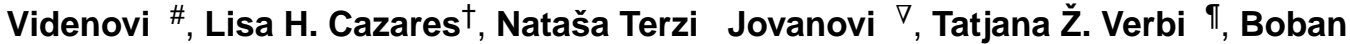

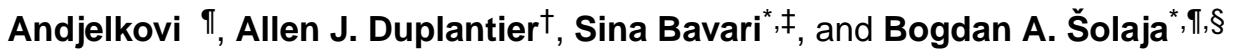 \\ IUniversity of Belgrade, Faculty of Chemistry, Studentski trg 16, P.O. Box 51, 11158, Belgrade, \\ Serbia \\ ¥Mouse Cancer Genetics Program, Center for Cancer Research, National Cancer Institute, \\ Frederick, Maryland 21702, United States \\ †Molecular and Translational Sciences Division, United States Army Medical Research Institute of \\ Infectious Diseases, 1425 Porter Street, Frederick, Maryland 21702, United States \\ \#Faculty of Chemistry Innovative Centre, Studentski trg 12 16, 11158 Belgrade, Serbia \\ $\nabla$ University of Belgrade, Institute of Chemistry, Technology, and Metallurgy, Njegoševa 12, 11000 \\ Belgrade, Serbia \\ ‡United States Army Medical Research Institute of Infectious Diseases, 1425 Porter Street, \\ Frederick, Maryland 21702, United States \\ §Serbian Academy of Sciences and Arts, Knez Mihailova 35, 11158 Belgrade, Serbia
}

\section{Abstract}

\footnotetext{
*Corresponding Author: For B.Š.: phone, +381-11-263-86-06; fax, +381-11-263-60-61; bsolaja@ chem.bg.ac.rs; bogdan.solaja@sanu.ac.rs.; For S.B.: phone, +1-301-619-4261; Fax: +1-301-619-2348; sina.bavari.civ@mail.mil. ORCID

Bogdan A. Šolaja: https://orcid.org/0000 000299752725

Author Contributions

B.Š and S.B. designed the research. Part of the projected dissertation of J.K., University of Belgrade. The manuscript was written by J.K. with contributions of all authors. All authors have given approval to the final version of the manuscript.

Notes

Opinions, interpretations, conclusions, and recommendations stated within the article are those of the authors and are not necessarily endorsed by the U.S. Army nor does mention of trade names, commercial products, or organizations imply endorsement by the U.S. Government. The authors declare no competing financial interest.

Supporting Information.

The following files are available free of charge.

Supporting information - I, PDF

Inhibitory activities against BoNT/A LC and holotoxin in proteolytic and cell-based assay for all tested compounds; fluorescence and UV-Vis spectra for determination of $\mathbf{1 6}$ binding to HSA and AGP; ligand interaction diagrams, docking scores and docking-in vitro inhibitory activity correlations; spectral and analytical data for all synthesized compounds; detailed procedures for the determination of the HPLC purity.

Supporting information - II, PDF

NMR spectra and HPLC purity spectra of all tested compounds.

Molecular Formula Strings, CSV
} 
The synthesis and inhibitory potencies against botulinum neurotoxin serotype A light chain (BoNT/A LC) using in vitro HPLC based enzymatic assay for various steroidal, benzothiophene, thiophene and adamantane 4 aminoquinoline derivatives is described. In addition, the compounds were evaluated for the activity against BoNT/A holotoxin in mouse embryonic stem cell derived motor neurons. Steroidal derivative $\mathbf{1 6}$ showed remarkable protection (up to $89 \%$ of uncleaved SNAP 25) even when administered 30 minutes post intoxication. This appears to be the first example of LC inhibitors antagonizing BoNT intoxication in mouse embryonic stem cell derived motor neurons (mES MNs) in a post-exposure model. Oral administration of $\mathbf{1 6}$ was well tolerated in the mouse up to $600 \mathrm{mg} / \mathrm{kg}$, qd. Although adequate unbound drug levels were not achieved at this dose, the favorable in vitro ADMET results strongly support further work in this series.

\section{TOC image}

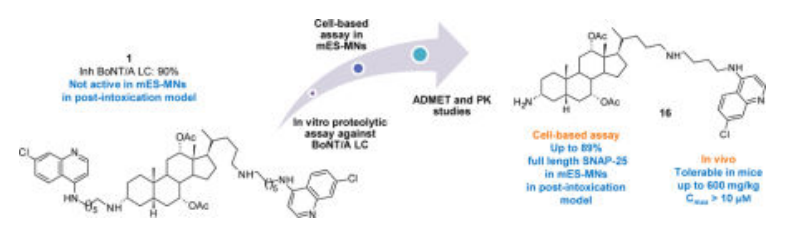

\section{INTRODUCTION}

Botulinum neurotoxins (BoNTs) are proteins produced by the Gram positive anaerobic bacterium Clostridium botulinum. They are amongst the most potent toxins known and are causative agents of botulism, a serious and life threatening illness in humans and animals. ${ }^{1}$ There are at least seven distinct serotypes (A G), however, three of them (A, B and E) are considered the most noxious in humans. ${ }^{2,3}$ The majority of efforts have been focused on identification of BoNT/A inhibitors with intracellular activity, because antibody based treatments were found successful only before toxin enters a neuron. ${ }^{4}$ Recent reviews have covered the in vitro in - vivo gap in this field, ${ }^{4}$ focusing on small molecule non-peptide inhibitors (SMNPI), potential drug targets and the MOA of these SMNPIs. ${ }^{5,6}$ Very recently, several approaches using SMNPIs have been explored by targeting the host intoxication pathways not by directly inhibiting the toxins' proteolytic activity but focusing on Src family kinase signaling, ${ }^{7}$ thioredoxin reductase system ${ }^{8,9}$ and by the development of phosphatase inhibitors that would have an impact on BoNT intoxication in motor neurons. ${ }^{10}$ The alternative approach was also developed, the inhibitors that interact with BoNT/A LC; among them the hydroxamates ${ }^{11}$ and aminoquinolines showed high inhibitory activities against BoNT/A LC in cell free assays. ${ }^{12-16}$ Diverse cell-based assays have been used as more relevant methods for evaluation of new drugs capable of protecting SNAP-25 from BoNT/A LC cleavage. ${ }^{17-20}$ More importantly, these methods simulate all key steps in intoxication process, starting from holotoxin binding to the cell surface to cleavage of the SNARE proteins. ${ }^{21,17}$ Since there is a continuous need for discovering new therapeutics for treatment of BoNT/A intoxication, this method is considered to be a very helpful tool for narrowing the spectrum of compounds for testing in animal models. Ex vivo assays, such as the mouse hemidiaphragm assay for BoNT/A induced muscle paralysis are also widely used for evaluating new drug candidates (e.g. quinolin 8 ol inhibitors ${ }^{22}$ and $\mathbf{E G A}^{23}$ ). Despite several attempts, ${ }^{23-27}$ there is still no inhibitor that is significantly effective in an animal 
model of intoxication, especially when administered post toxin injection. Recently published complexes of $\mathrm{Cu}$ (II) with dithiocarbamate and bis(thiosemicarbazone) are also only capable of extending time to death of BoNT/A intoxicated mice. ${ }^{28}$ Similarly, newly published mercaptoacetamide inhibitor ABS 252 proved to be effective in extending survival of BoNT intoxicated mice. ${ }^{29}$ Presently, the only SMNPI with anti-BoNT/A activity in the mouse model is Dyngo-4a which administered $3 \mathrm{~h}$ post-intoxication provides $30 \%$ mice survival for $24 \mathrm{~h} .{ }^{30}$ For the treatment of BoNT intoxication, it is necessary for inhibitors to reach the neuromuscular junction and enter the neuronal cell. Thus, adequate drug exposure at the target tissue is key, and in vitro ADMET parameters such as solubility, microsomal stability, permeability and plasma protein binding can be used as an effective means to down select active compounds capable of providing acceptable PK properties.

We designed our new BoNT/A LC inhibitors according to structure-based docking simulations. ${ }^{16}$ Since docking simulations indicated that besides steroids the benzothiophene derivatives of aminoquinoline also fit into the binding cleft of BoNT/A LC (keeping the main interactions with amino acid residues within the active site, c.f. Supporting information), we decided to investigate the contribution of other carriers to the inhibitory activity (Chart 1).

Here, we report on the synthesis, pharmacokinetic analysis and detailed evaluation of new steroidal, benzothiophene, thiophene and adamantane 4 aminoquinoline inhibitors of BoNT/A LC and their respective inhibitory potencies against BoNT/A holotoxin in mouse embryonic stem cell derived motor neurons (mES MNs).

\section{CHEMISTRY}

Continuing our search for efficient BoNT/A inhibitors, we report on new steroidal derivatives with improved inhibitory activities against BoNT/A LC. Here, we focus on steroidal derivatives with a basic amino group at $\mathrm{C}(3)$, varying the linker connecting the steroidal and aminoquinoline components. Also, we examined three other classes of aminoquinoline derivatives with benzothiophene, thiophene and adamantane carriers for their inhibitory activities against BoNT/A LC. All steroidal, benzothiophene, thiophene and adamantane derivatives were synthesized according to our established procedures (Schemes 1 and 3). ${ }^{16,31,32}$ All tested inhibitors were fully characterized and their purities were $>95 \%$ (as determined by HPLC, Supporting Information).

Based on our earlier findings, ${ }^{16}$ the newly synthesized steroidal inhibitors were chosen for essential SAR studies within the series. To that purpose, we varied the substitution at carbon atoms next to nitrogens, at $\mathrm{N} \mathrm{C}(24)$ and substitution at quinoline $\mathrm{C}(7)$ position. Steroidal derivatives were obtained by reductive amination starting from $\mathrm{C}(24)$ alcohol derivative $3 .{ }^{16}$ After removal of protecting group, compounds 14, 16, 17 and 19-23 were obtained in moderate to excellent yield (48-97\%). In addition, subjecting the Boc-protected derivatives to reductive amination with $37 \%$ formaldehyde and $\mathrm{NaBH}_{3} \mathrm{CN}$ followed by removal of the protecting group afforded $\mathrm{N}$-methylated derivatives $\mathbf{1 5}$ and $\mathbf{1 8}$ in acceptable yields (56$60 \%)$. Due to the presence of the methyl group at $\mathrm{N}-\mathrm{C}(\mathrm{a})$, compounds 17-21 were obtained as mixture of diastereomers and were tested as such (vide infra). According to our docking 
model only $\mathrm{C}(7)$ (and not (C12)) acetoxy group is directing structural element featuring the $\mathrm{Zn}^{2+}$ chelation so favorably contributing to inhibitor's diving into catalytic cleft (Fig. S11S13). ${ }^{16}$ The inhibitor $\mathbf{2 4}(68 \%)$ was obtained by hydrolysis of acetoxy groups in $\mathbf{1 6}$ with potassium hydroxide in methanol (Scheme 1).

Steroidal derivative $\mathbf{3 0}$ with the amide functional group next to quinoline was prepared in order to explore the effect of changes in $\mathrm{p} K_{\mathrm{a}}$ and conformation on inhibitory activity. $N$-Boc protected derivative 29 was obtained in $43 \%$ yield by reductive amination of steroidal C(24) aldehyde and amine $\mathbf{2 8}$ (prepared in few steps starting from 4,7-dichloroquinoline). It has been noticed that amine $\mathbf{2 8}$ decomposes to $\mathbf{2 5}$ and pyrrolidine 2-one, therefore, it was used in next step without detailed characterization. The final compound $\mathbf{3 0}$ was obtained in good yield (80\%) after removal of the Boc protecting group (Scheme 2).

Synthesis of novel benzothiophene and thiophene derivatives is presented in Scheme 3. Benzothiophene and thiophene derivatives 33, 34, 42-45 and $\mathbf{5 0}$ were obtained by reductive amination from corresponding aldehydes $(\mathbf{3 1}, \mathbf{3 9 - 4 1}$ and $\mathbf{4 9})$ in moderate yield (12-77\%). Compound 47 was obtained from $\mathbf{4 5}$ after removal of TMS-group in moderate yield. Benzothiophene and thiophene $N$-methyl tertiary amino derivatives, 37, 38 and 48 were synthesized by reaction of formaldehyde with secondary amines 35,36 and $\mathbf{4 6}$ respectively, reported in our previous work. ${ }^{31,33}$

Syntheses of novel adamantane derivatives are presented in Scheme 4. Adamantane derivatives with tertiary nitrogen $\mathbf{5 6 - 6 5}, 68$ and 69 were obtained using the same procedures as mentioned above in moderate to excellent yield (55-93\%) after coupling of prepared amines (51-55, AQ11, AQ7, AQ8) $)^{13,32,34}$ to corresponding aldehydes. Key reaction for synthesis of adamantane derivatives 77-82 was the Pd-mediated Buchwald coupling of previously prepared amines (70-75 $)^{32}$ to 4-chloroquinoline in moderate to excellent yield (44-91\%). Compounds 84 and $\mathbf{8 5}$ were obtained in high yield by methylation of compounds 78 and 83 , respectively.

\section{RESULTS}

Recently, we discovered steroidal bis-aminoquinoline (bis-ACQ) inhibitors with 90-97\% BoNT/A LC inhibition and $\mathrm{K} i$ values within the range 0.103-0.389 $\mu \mathrm{M}$ (such as 1, Chart 1). ${ }^{16}$ However, several comments regarding our hit compounds should be considered. Simplifying the original structure should be desired since the synthesis of bis-ACQ derivatives and purification thereof is rather demanding task. In addition, the compounds with MW > 900, although of natural product origin, are not commonly considered drug-like and could have difficulties in reaching the target as well. Therefore, we have chosen the compound 2 (Chart 1), ${ }^{16}$ with $\mathrm{IC}_{50}=0.81 \mu \mathrm{M}$ and $\mathrm{K} i=3.22 \mu \mathrm{M}$ in HPLC-based assay and $77 \%$ of SNAP-25 protection at $30 \mu \mathrm{M}$ in pre-intoxication scenario in embryonic chicken spinal primary neurons as very promising starting point for further improvement of the steroidal inhibitors. 


\section{Evaluation of Inhibitory Activity Against BoNT/A LC}

Inhibitory activities against BoNT/A LC in proteolytic and against holotoxin in cell-based assay are presented in Table 1. In vitro activities for all other compounds that were evaluated only against BoNT/A LC are given in Supporting Information (Table S1).

We employed a well-defined 17-mer peptide (termed P39, acetyl-

SNKTRIDEANQRATKML-amide, that contains the SNAP-25 scissile bond) ${ }^{35}$ HPLC-based proteolytic assay. Synthesized steroidal derivatives have shown BoNT/A LC inhibition up to $85 \%$ at a standard $20 \mu \mathrm{M}$ concentration (compound $\mathbf{1 8}$ ) and $\mathrm{IC}_{50}$ values ranging from $0.7-$

$7.1 \mu \mathrm{M}$ (Table 1, Table S1). Our control compound 1, in the current proteolytic HPLC-based assay showed $90 \%$ inhibition of BoNT/A LC at $20 \mu \mathrm{M}$, in excellent agreement with results reported previously (95\% of inhibition). ${ }^{16}$ Compound $\mathbf{2 4}$ with hydroxy groups at $\mathrm{C}(7)$ and $\mathrm{C}(12)$, with $48 \%$ inhibition of BoNT/A LC appeared to be much less potent than other steroidal derivatives. The negative effect of the amide functionality on BoNT/A LC inhibition (30,37\%) was also observed. Introduction of a methyl group into the linker or secondary nitrogen and changing its position, as well as the variations in the presence of chlorine atom at the quinoline moiety influenced the inhibitory activity to certain extent.

Benzothiophene derivatives showed good inhibition activities too, with $\mathrm{IC}_{50}$ values ranging within 3.3-10.2 $\mu \mathrm{M}$, thus being comparable to the steroidal series. By changing the position of cyano group from $\mathrm{C}(6)$ to $\mathrm{C}(5)$ the inhibition at $20 \mu \mathrm{M}$ concentration was sharply improved (Table 1, Table S1, compounds 36 (61\%), 87 (75\%), 86 (84\%) vs 88 (23\%), 89 $(8 \%))$.

Derivatives with cyano group instead of fluorine atom at C(5), showed higher degree of inhibition (Table 1, Table S1, compounds 86 (84\%), 87 (75\%) vs 35 (34\%), 90 (56\%)), while the compounds without tertiary nitrogen appeared to be more active at $20 \mu \mathrm{M}$ concentration than their methylated analogs (Table 1, Table S1, compounds 91 (69\%), 36 (61\%) vs $92(48 \%), 38(27 \%))$. In thiophene series, the most potent inhibitors proved to be 46 and 93 with cyano substituent and long methylene linker (6 and 8 methylene groups and $70-80 \%$ and $77 \%$ of inhibition, respectively). Compound 46 (MV150) with $70-80 \%$ of inhibition has been utilized as positive control, for evaluating the performance of the 17-mer HPLC-based proteolytic assay. Changing the position of aminoquinoline linker connection to phenyl moiety from para- to meta- had no significant effect on inhibitory activity (Table 1, $46(70-80 \%)$ vs $\mathbf{5 0}(68 \%))$. Improvement of the inhibitory activity was observed in derivatives without chlorine atom at $\mathrm{C}(7)$ position of aminoquinoline or without tertiary nitrogen (Table 1, Table S1, compounds 93 (77\%), 46 (70-80\%) vs 94 (14\%), 95 (30\%) and $96(35 \%), 48(55 \%))$. In addition, cyano derivatives were found to be superior inhibitors than their ethynyl analogs (Table 1, Table S1, compounds 97 (36\%), 46 (70-80\%) vs 47 (19\%), $98(53 \%)$ ). Examined adamantane derivatives bearing chlorine atom on aminoquinoline moiety proved to be more active in the HPLC-based proteolytic assay than their des-chloro analogs (Table 1, Table S1, compounds 57 (71\%), 60 (67\%), 99 (64\%) vs 69 (31\%), 85 $(51 \%), \mathbf{1 0 0}(42 \%)$ and other analogs), and that differs from the previously mentioned thiophene series. Tertiary nitrogen and chlorine atom at $\mathrm{C}(7)$ of aminoquinoline moiety 
together had the most favorable effect on the inhibitory activity (57 and $\mathbf{6 0}, 71 \%$ and $67 \%$ of inhibition, respectively, Table 1).

In addition, experimental $\log D$ values are presented in Table $1 . \log D$ values are obtained using reversed-phase thin-layer chromatography at two different $\mathrm{pH}$ : $\mathrm{pH}=1(\mathrm{MeOH} / \mathrm{HCl}$ (70/30)) for compounds $14-19,24,46,50,93,96$ and 101 and $\mathrm{pH}=10$ (acetone/ $/ \mathrm{NH}_{3} / \mathrm{H}_{2} \mathrm{O}$ $(85 / 5 / 10)$ ) for compounds $34, \mathbf{3 6 - 3 8}, \mathbf{5 7}, \mathbf{6 0}, \mathbf{8 6}, \mathbf{8 7}, \mathbf{9 1}, \mathbf{1 0 2}-\mathbf{1 0 6} .{ }^{36}$ For compound $16 \log D$ was also determined at physiological $\mathrm{pH}=7.3$, using shake flask method (octanol/TBS buffer). ${ }^{37-39}$

\section{Inhibitory Activity Against Holotoxin in mES-MNs}

Pre-intoxication model-Based on the activity in primary screen and structural diversity (Table 1, Table S1), 30 compounds were chosen for secondary screening in cell-based assay in mouse ES-cell derived motor neurons (mES-MNs) in pre-intoxication model at two concentrations -10 and $20 \mu \mathrm{M}$ (Table 1). SNAP-25 protein cleavage was measured by Western-blot analysis. In this model, compounds were added 30 minutes prior to holotoxin $(500 \mathrm{pM})$ and intoxicated for 4 hours. Inhibitors tested during BoNT/A challenge in $\mathrm{mES}$ MNs in pre-intoxication model were found to afford uncleaved SNAP-25 up to $88 \%$ at 20 $\mu \mathrm{M}$ concentration (compound 16), with steroidal compounds being generally the most promising.

In contrast to in vitro results, using this assay we can substantially differentiate our steroidal inhibitors from benzothiophene derivatives, which were capable to protect SNAP-25 from cleavage up to $68 \%$ at $20 \mu \mathrm{M}$ concentration. Another issue is important to note benzothiophene derivatives $(\mathbf{3 6}, \mathbf{8 6}$ and $\mathbf{8 7})$ with cyano instead of fluorine substituent were much less active despite the high percent of inhibition in HPLC-based assay. In addition, in this model the compound $\mathbf{3 8}$, shows significantly higher protection of SNAP-25 in comparison with non-methylated analogues, although it would be eliminated based on its poor inhibitory activity (27\%) in primary screening. Three thiophene derivatives have shown to be capable of protecting SNAP-25 from cleavage more than $60 \%$ at $20 \mu \mathrm{M}$ concentration $(\mathbf{5 0}, 93$ and $\mathbf{9 6})$, while adamantane derivatives were found to be less active, despite promising results obtained in primary screening. Only one adamantane 60, showed $72 \%$ protection of SNAP- 25 at $20 \mu \mathrm{M}$.

Twelve compounds with good results obtained in pre-intoxication model (56-88\% SNAP-25 protection at $20 \mu \mathrm{M}$ concentration, Table 1) were subjected to pre-exposure dose-response experiment in concentration range from 0.1 to $20 \mu \mathrm{M}$ (Figure 1). The results obtained in dose-response experiment at $20 \mu \mathrm{M}$ concentration are similar to those obtained in the initial experiment at two concentrations, given in Table 1. The obtained dose-response results clearly indicate that introduction of chlorine atom at $\mathrm{C}(7)$ position of quinoline moiety highly improved the activity of steroidal inhibitors (16 vs $\mathbf{1 4}$; $\mathrm{IC}_{50} \sim 10 \mu \mathrm{M}$ vs $\mathrm{IC}_{50}=10-20$ $\mu \mathrm{M}$, respectively). Another pair of derivatives, 19 with methyl group next to $\mathrm{N}-\mathrm{C}(24)$ and $\mathbf{1 7}$ with methyl group next to quinoline moiety, also merit attention. Significantly higher protection of SNAP-25 is observed with 19 at $20 \mu \mathrm{M}$ concentration, while at lower concentrations both derivatives exhibited comparable inhibitory activity. Except mentioned 
four steroidal derivatives, compound $\mathbf{1}$ showed remarkable activity in pre-intoxication scenario $\left(\mathrm{IC}_{50}<10 \mu \mathrm{M}\right)$. As the inhibitor $\mathbf{2 4}$ could arise as putative metabolite in vivo, despite its lower activity in HPLC-proteolytic assay compared to other steroidal derivatives, we were intrigued by moderate activity of this compound in pre-intoxication model (58\% at $16 \mu \mathrm{M}$, Table 1). Tested at nine concentrations 0.25 to $64 \mu \mathrm{M}$ it also showed dose-dependent behavior, with $\mathrm{IC}_{50}=8-16 \mu \mathrm{M}$ (Figure S1, Table S5). Benzothiophene derivatives $\mathbf{3 4}$ and $\mathbf{3 8}$ showed $\mathrm{IC}_{50}$ values in 10-20 $\mu \mathrm{M}$ range. In addition, three thiophene (50,93 and $\left.\mathbf{9 6}\right)$ and two adamantane (57 and 60) 4-aminoquinoline derivatives were evaluated in dose-dependent preintoxication model, in order to examine the scope of carriers coupled to aminoquinoline moiety. To our pleasure, not only steroidal and benzothiophene aminoquinolines showed remarkable activities in dose-dependent manner, but also thiophene and adamantane derivatives. As one can find in Figure 1, 60 has shown the highest protection of SNAP-25 at $20 \mu \mathrm{M}$ concentration (90\%) and $\mathrm{IC}_{50}<10 \mu \mathrm{M}$. Good dose-response and high percent of inhibition is also seen for 93 and $96\left(\mathrm{IC}_{50}=1020 \mu \mathrm{M}\right.$ and $\mathrm{IC}_{50}=5-10 \mu \mathrm{M}$, respectively).

Post-intoxication model-The most effective derivatives were tested postsymptomatically (in triplicate, 30 and 60 minutes following $500 \mathrm{pM}$ holotoxin administration) at $20 \mathrm{pM}$ concentration (Figure 2). Compound 60, which was the foremost candidate in pre-intoxication model, unfortunately failed in post-exposure model with only $15 \%$ of intact SNAP-25. From all tested derivatives, compound 16 highlights with $64 \%$ of SNAP-25 cleavage protection when administered 30 minutes post-intoxication, and $45 \%$ protection when neurons were treated 60 minutes after BoNT/A administration. Other derivatives were significantly less active, with steroidal series still being the most promising.

Since compound $\mathbf{1 6}$ showed excellent behavior in post-intoxication scenario (Figure 2 and Figure S2, Table S6), and compound $\mathbf{2 4}$ is considered as a potential metabolite which is reasonable to expect to be formed in mouse gut and liver, we subjected both $\mathbf{1 6}$ and $\mathbf{2 4}$ to 30 minutes post-exposure dose-response experiment. Compounds were tested in duplicate at 9 concentrations, starting from $0.25 \mu \mathrm{M} \rightarrow 64 \mu \mathrm{M}$ (Figure 3). In this run 16 exhibited a dosedependent protection of SNAP-25, with $\mathrm{IC}_{50} \sim 8 \mu \mathrm{M}$. To the best of our knowledge, this is the most active small-molecule inhibitor of BoNT/A LC in post-intoxication scenario in mES-MNs (89\% of full length SNAP-25 at $32 \mu \mathrm{M}$ ). The activity of compound 24 in mESMNs (69\% full length SNAP-25 at $64 \mu \mathrm{M}$ ) was somewhat surprising; however, observation that both, the compound $\mathbf{1 6}$ and its putative metabolite were active in mES-MNs strongly supports further examination of biological activity.

\section{Toxicity studies}

In vivo toxicity studies of several derivatives subjected to post-intoxication assay was estimated in a mouse model. As can be seen from Table 2, 16, 34, 93 and 96 proved to be completely non-toxic at the given dose (all 5 mice survived 30 days after administration and showed normal appearance and behavior).

In the separate host toxicity studies, two groups of 5 healthy mice were subjected to oral administration of the compound $\mathbf{1 6}$ at higher concentrations (400 and $600 \mathrm{mg} / \mathrm{kg}$, single 
dose), and even at the highest applied concentration, $\mathbf{1 6}$ proved to be non-toxic (all 5 mice survived 30 days after administration and showed normal appearance and behavior).

\section{Pharmacokinetic Analysis of Compound 16}

ADMET parameters-Given its ability to antagonize BoNT/A in mES-MNs in postintoxication model (in full accordance with previous step analyses), $\mathbf{1 6}$ appeared as the best candidate for further testing. ADMET parameters for this compound are presented in Table 3. Compound $\mathbf{1 6}$ showed good stability in both human and mouse liver microsomes (halflife $>60 \mathrm{~min}$ ) and very good stability in human plasma ( $>85 \%$ remaining at $1 \mathrm{~h}$ ). It showed solubility $>50 \mu \mathrm{g} / \mathrm{mL}$ (Table 3 ) as determined by laser nephelometry and confirmed by more precise shake-flask method with spectrofluorimetric detection $(640 \mu \mathrm{g} / \mathrm{mL})$. In MDR1MDCK permeability assay, 16 showed excellent tissue penetration $\left(45.3 \times 10^{-6} \mathrm{~cm} / \mathrm{s}\right.$ in $\mathrm{A} \rightarrow \mathrm{B}$ direction and $24.6 \times 10^{-6} \mathrm{~cm} / \mathrm{s}$ in $\mathrm{B} \rightarrow \mathrm{A}$ direction). It acts as moderate to poor inhibitor of five CYP450 enzymes (which play important role in the drug metabolism). One in vitro parameter possibly limiting this compound as potential drug is high plasma protein binding, $>99 \%$ according to equilibrium dialysis method. However, the efficacy of the drug transport could not be attributed to the PPB only; instead, the binding constants with major transporters in the blood should be considered. In addition to dialysis, the interaction between 16 and HSA and AGP proteins has been studied by monitoring the changes in fluorescence spectrum of HSA and AGP upon addition of increasing amounts of $\mathbf{1 6}$ ( $K_{\mathrm{sv}}$ $=(4.56 \pm 0.27) \times 10^{4}$ for HSA; $K_{\mathrm{sv}}=(6.99 \pm 0.25) \times 10^{5}$ for AGP $)$.

In Vivo Mouse Pharmacokinetics-Aminoquinoline $\mathbf{1 6}$ was selected for determination of concentration levels in mouse serum and evaluation of plasma protein binding due to its promising activity in mES-MNs, non toxicity, and very good ADMET properties.

Compound 16 was dosed orally, in a single dose, at two different concentrations - 400 and $600 \mathrm{mg} / \mathrm{kg}$ to groups of 7 and 6 mice, respectively. For both doses, maximal concentration of the drug in the blood was determined by UPLC-MS/MS in samples previously treated with acetonitrile $(15 \rightarrow 120 \mathrm{~min}$, Table 4 and Figure 4$)$.

Obtained in vivo pharmacokinetic properties are summarized in Table 5. In addition, mice samples were analyzed for compound $\mathbf{2 4}$, monoacetylated analogue and corresponding $\mathrm{M}$ +16 and M+32 metabolites, in order to examine possible deacetylation in the mouse gut.

None of these metabolites were detected.

\section{DISCUSSION}

Logical step in the investigation of drug's anti BoNT/A potential was the evaluation of the candidates in a cell-based assay using mES-MNs, since they mimic the whole intoxication process. We proved that our inhibitors protect SNAP-25 from cleavage in a dose-dependent manner, when administered prior to holotoxin (Figure 1). Thiophene derivative 96 has shown the $\mathrm{IC}_{50}=510 \mu \mathrm{M}$, benzothiophene derivatives $\mathbf{3 4}$ and $\mathbf{3 8} \mathrm{IC}_{50}=10-20 \mu \mathrm{M}$ and among steroidal derivatives 16 singled out with $\mathrm{IC}_{50} \sim 10 \mu \mathrm{M}$. Adamantane derivative 60 seemed to be the favorable candidate with $90 \%$ of SNAP- 25 protection at $20 \mu \mathrm{M}$ and $\mathrm{IC}_{50}<$ $10 \mu \mathrm{M}$. The discrepancy between results obtained in proteolytic HPLC-based assay and in 
mES-MNs for cyano derivatives 36, 86 and $\mathbf{8 7}$ (61-84\% inhibition vs 26-53\% SNAP-25 protection at $20 \mu \mathrm{M}$ ) could be attributed to their inability to enter the neurons. Regarding compound 38 different MoA might be considered since this compound does not act as LC inhibitor (27\% inhibition, Table 1) but it moderately protects SNAP-25 in mES-MNs in preintoxication scenario $\left(\mathrm{IC}_{50}=1020 \mu \mathrm{M}\right.$, Figure 1).

Pre-exposure model for BoNT/A intoxication is very convenient for discovering drugs with good permeability, and the results of inhibitory activities could be useful for prophylactic purposes. More significant challenge is post-exposure model, which demonstrates the ability of compound to protect SNAP-25 from BoNT/A cleavage after holotoxin endocytosis. Noteworthy results of our inhibitors in post-intoxication model in mES-MNs offered us valuable information that newly synthesized derivatives not only enter the cells, but also very probably inhibit to great extent the BoNT/A LC inside the neuronal cytosol. From all examined derivatives, we managed to select steroidal compound 16 which antagonizes BoNT/A holotoxin up to $89 \%$ at $32 \mu \mathrm{M}$ when administered 30 minutes post-intoxication. More importantly, the essential difference between our previous hit bis-ACQ compounds came out - compound $\mathbf{1}$ with $<40 \%$ protection failed in post-intoxication scenario, thus justifying the synthesis of novel C(3)-amino derivatives.

In the early stages of drug discovery, the optimization of physicochemical properties (e.g. lipophilicity) can greatly improve a compound's chance in obtaining the proper balance among permeability, solubility and metabolism; and the experimental $\log D$ of 2.07 (pH=7.3) obtained for compound $\mathbf{1 6}$ was considered optimal in that regard. ${ }^{41}$ Subsequent ADMET and PK studies were performed in order to determine if compound $\mathbf{1 6}$ was capable of providing adequate drug exposure. As supported by its $\log D$ value, compound 16 displayed favorable ADMET properties. In an MDR1/MDCK assay it showed permeability constant $\mathrm{P}_{\text {app }}>20$, predictive for good tissue penetration and the efflux ratio $<<2.5$, thus not being a substrate for P-gp. PPB for this compound was estimated to $>99 \%$ according to equilibrium dialysis method, however, spectrofluorimetric measurements of $\mathbf{1 6}$ binding for HSA and AGP, indicate that interaction between $\mathbf{1 6}$ and plasma proteins is optimal to enable transport of the drug and to release it at its target $\left(K_{\mathrm{sv}}=10^{4}-10^{6}\right)$. This experimental observation is supported by detailed reviews on albumin-drug and AGP-drug interactions. ${ }^{42-44}$ Due to its nontoxicity in vivo at very high concentration (up to $600 \mathrm{mg} / \mathrm{kg}$ ), we provided pharmacokinetic analysis in mice. Compound 16 administered at $600 \mathrm{mg} / \mathrm{kg}$ dose provides $\mathrm{C}_{\max }$ up to $11.9 \mu \mathrm{M}(8.5 \mu \mathrm{g} / \mathrm{mL}$, Table 4$)$ and is detectable in mouse serum up to 120 min after administration (Figure 4). Unfortunately, detailed PK analysis was published only for few inhibitors submitted to in vivo studies, so detailed analysis and comparison with $\mathbf{1 6}$ is not possible. ${ }^{4}$

\section{CONCLUSION}

Synthesized compounds antagonize BoNT/A LC and BoNT/A in mES-MNs in a dosedependent manner in both pre- and post-intoxication models. To the best of our knowledge, this is the first example of LC inhibitors antagonizing BoNT intoxication in mouse ES-cell derived motor neurons in a post-exposure model (few SMNPIs of BoNT/A LC active in embryonic chick spinal motor neurons were reported previously ${ }^{45}$ ). Compound 16 proved to 
be potent inhibitor of BoNT/A holotoxin in mES-MNs in post-intoxication scenario and well tolerated in the mouse up to $600 \mathrm{mg} / \mathrm{kg}$, p.o. Binding constants with major transporters in blood (HSA and AGP) are within desirable values, suggesting that inspite of high PPB it could be delivered to its target. With very good ADMET properties and a plasma Cmax $>10$ $\mu \mathrm{M}$ in mice after oral administration, we believe that compound $\mathbf{1 6}$ has distinguished itself from other lead BoNT inhibitors in the literature. ${ }^{4}$ Current efforts are focused on reducing protein binding, determining/mitigating the clearance route of $\mathbf{1 6}$ in mouse and determining if optimal formulation and/or subcutaneous administration could improve its PK profile and merit testing in a mouse lethality model. Noteworthy, there are no post symptomatically administered LC inhibitors to date that are significantly efficacious in a mouse model of BoNT intoxication. ${ }^{4}$

\section{EXPERIMENTAL SECTION}

\section{Chemistry}

Melting points were determined on a Boetius PMHK apparatus and were not corrected. IR spectra were recorded on a Thermo-Scientific Nicolet 6700 FT-IR diamond crystal spectrophotometer. ${ }^{1} \mathrm{H}$ and ${ }^{13} \mathrm{C}$ NMR spectra were recorded on a Varian Gemini-200 spectrometer (at 200 and $50 \mathrm{MHz}$, respectively), and a Bruker Ultrashield Advance III spectrometer (at 500 and $125 \mathrm{MHz}$, respectively) in the indicated solvent (vide infra) using TMS as the internal standard. Chemical shifts are expressed in ppm ( $\delta$ ) values and coupling constants ( $J$ in Hz. ESI-MS (HRMS) spectra of the synthesized compounds were acquired on a Agilent Technologies 1200 Series instrument equipped with Zorbax Eclipse Plus C18 $(100 \times 2.1 \mathrm{~mm}$ i.d. $1.8 \mu \mathrm{m})$ column and DAD detector $(190-450 \mathrm{~nm})$ in combination with a 6210 Time-of-Flight LC/MS instrument in positive and negative ion mode. The samples were dissolved in $\mathrm{MeOH}$ (HPLC grade). The selected values were as follows: capillary voltage $4 \mathrm{kV}$; gas temperature $350{ }^{\circ} \mathrm{C}$; drying gas $12 \mathrm{~L} \mathrm{~min}^{-1}$; nebulizer pressure $45 \mathrm{psig}$; fragmentator voltage: $70 \mathrm{~V}$. Mass spectral analyses were done using electrospray ionization in positive ion mode on a Surveyor separations module coupled to a ThermoFinnigan TSQ AM triple quadrupole mass spectrometer. Gas chromatography tandem mass spectrometry (GC-MS) analyses were performed on an Agilent 7890A GC (Agilent) system equipped with a 5975C inert XL EI/CI MSD and a flame ionization detector (FID) connected by capillary flow technology through a 2-way splitter with make-up gas. An HP-5 MS capillary column (Agilent Technologies, $25 \mathrm{~mm}$ i.d., $30 \mathrm{~m}$ length, $0.25 \mu \mathrm{m}$ film thickness) was used. The flash chromatography was performed on Biotage SP1 system equipped with UV detector and FLASH 12+, FLASH 25+ or FLASH 40+ columns charged with KP-SIL (40 $63 \mu \mathrm{m}$, pore diameter $60 \AA$ ), KP-C18-HS ( 40 - $63 \mu \mathrm{m}$, pore diameter $90 \AA$ ) or KP-NH (40 $63 \mu \mathrm{m}$, pore diameter $100 \AA$ ) as an adsorbent. Elemental analyses were realized with an Elemental Vario EL III microanalyser. Compounds were analyzed for purity (HPLC) using a Agilent 1200 HPLC system equipped with Quat Pump (G1311B), Injector (G1329B) 1260 ALS, TCC 1260 (G1316A) and Detector 1260 DAD VL+ (G1315C). Compound 42 was analyzed for purity (HPLC) using Waters 1525 HPLC dual pump system equipped with an Alltech, Select degasser system, and dual $\lambda 2487$ UV VIS detector. All tested inhibitors were fully characterized and their purities were $>95 \%$ (as determined by HPLC, c.f. Supporting Information). HPLC analysis was performed in two diverse systems for each 
compound. Specific HPLC methods are as follows: Method A: Zorbax Eclipse Plus C18 4.6 $\times 150 \mathrm{~mm}, 1.8 \mu$, S.N. USWKY01594 was used as the stationary phase. Eluent was made from the following solvents: $0.2 \%$ formic acid in water (A) and methanol (B). The analysis were performed at the UV max of the compounds (at $330 \mathrm{~nm}$ for compounds 14-16, 18, 19, $\mathbf{2 2}, \mathbf{2 3}, \mathbf{3 4}, \mathbf{3 7}, \mathbf{3 8}, \mathbf{5 0}, \mathbf{5 6}-\mathbf{6 5}, \mathbf{6 6}-\mathbf{6 9}, \mathbf{7 7 - 8 2}, \mathbf{8 4}, \mathbf{8 5}$ and 93 , and at $254 \mathrm{~nm}$ for compound 17) to maximize selectivity. Compounds were dissolved in methanol, final concentrations were $\sim 1 \mathrm{mg} / \mathrm{mL}$. Flow rate was $0.5 \mathrm{~mL} / \mathrm{min}$. Method B: Zorbax Eclipse Plus C18 $4.6 \times 150 \mathrm{~mm}$, $1.8 \mu$, S.N. USWKY01594 was used as the stationary phase. Eluent was made from the following solvents: $0.2 \%$ formic acid in water (A) and acetonitrile (B). The analysis were performed at the UV max of the compounds (at $330 \mathrm{~nm}$ for compounds 14-19, 22, 23, 34, $\mathbf{3 7}, \mathbf{3 8}, \mathbf{4 4}, \mathbf{5 0}, \mathbf{5 6}-\mathbf{6 5}, \mathbf{6 6}-69,77-82,84,85$ and 93 ) to maximize selectivity. Compounds were dissolved in methanol, final concentrations were $\sim 1 \mathrm{mg} / \mathrm{mL}$. Flow rate was $0.5 \mathrm{~mL} /$

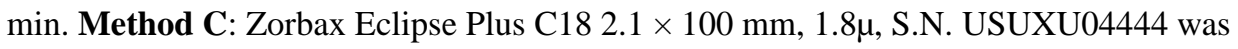
used as the stationary phase. Eluent was made from the following solvents: $0.2 \%$ formic acid in water (A) and methanol (B). The analysis was performed at the UV max of the compound (at $330 \mathrm{~nm}$ for compounds $\mathbf{2 0}, \mathbf{2 1}, \mathbf{2 4}, \mathbf{4 3}, \mathbf{4 4}, \mathbf{4 7}$; at $270 \mathrm{~nm}$ for compound $\mathbf{3 0}$, and at 254 $\mathrm{nm}$ for compound $\mathbf{3 3}$ ) to maximize selectivity. Compound was dissolved in methanol, final concentration was $\sim 1 \mathrm{mg} / \mathrm{mL}$. Flow rate was $0.2 \mathrm{~mL} / \mathrm{min}$. Method D: Zorbax Eclipse Plus C18 $2.1 \times 100 \mathrm{~mm}, 1.8 \mu$, S.N. USUXU04444 was used as the stationary phase. Eluent was made from the following solvents: $0.2 \%$ formic acid in water (A) and acetonitrile (B). The analysis was performed at the UV max of the compound (at $254 \mathrm{~nm}$ for compounds $\mathbf{2 0 , 2 4}$, 33; at $270 \mathrm{~nm}$ for compound 30 and at $330 \mathrm{~nm}$ for compounds 21, 43 and 47) to maximize selectivity. Compound was dissolved in methanol, final concentration was $\sim 1 \mathrm{mg} / \mathrm{mL}$. Flow rate was $0.2 \mathrm{~mL} / \mathrm{min}$. Method E: Poroshell $120 \mathrm{EC}-\mathrm{C} 18,4.6 \times 50 \mathrm{~mm}, 2.7 \mu, \mathrm{S} . \mathrm{N}$. USCFU07797 was used as the stationary phase. Eluent was made from the following solvents: $0.2 \%$ formic acid in water (A) and acetonitrile (B). The analysis was performed at the UV max of the compound ( $330 \mathrm{~nm}$ for compound 48 ) to maximize selectivity. Compound was dissolved in methanol, final concentration was $\sim 1 \mathrm{mg} / \mathrm{mL}$. Flow rate was 0.5 $\mathrm{mL} / \mathrm{min}$. Method F: Poroshell 120 EC-C18, $4.6 \times 50 \mathrm{~mm}, 2.7 \mu$, S.N. USCFU07797 was used as the stationary phase. Eluent was made from the following solvents: $0.2 \%$ formic acid in water (A) and methanol (B). The analysis was performed at the UV max of the compound (330 nm for compound 48) to maximize selectivity. Compound was dissolved in methanol, final concentration was $\sim 1 \mathrm{mg} / \mathrm{mL}$. Flow rate was $0.5 \mathrm{~mL} / \mathrm{min}$. Method G: Symmetry C18, $4.6 \times 150 \mathrm{~mm}, 5 \mu \mathrm{m}$, S.N. 02133627813637 was used as the stationary phase. Eluent was made from the following solvents: $0.2 \%$ formic acid in water (A) and methanol (B). The analysis was performed at the UV max of the compound ( $340 \mathrm{~nm}$ for compound $\mathbf{4 2}$ ) to maximize selectivity. Compound was dissolved in methanol, final concentration was $\sim 1$ $\mathrm{mg} / \mathrm{mL}$. Method H: Nucleosil C18, $4 \times 150 \mathrm{~mm}, 5 \mu \mathrm{m}$ was used as the stationary phase. Eluent was made from the following solvents: $0.2 \%$ formic acid in water (A) and methanol (B). The analysis was performed at the UV max of the compound (340 $\mathrm{nm}$ for compound 42) to maximize selectivity. Compound was dissolved in methanol, final concentration was $\sim 1 \mathrm{mg} / \mathrm{mL}$. 
Procedure A: General procedure for the synthesis of $\mathrm{N}$-Cbz protected aminoquinolines 107 and $109^{13}$

The mixture of 4,7-dichloroquinoline/4-chloroquinoline (1 equiv) and mono-Cbz protected diaminoalkane $\left(1.1-1.2\right.$ equiv) was slowly heated to $80^{\circ} \mathrm{C}$ for $1 \mathrm{~h}$, and the mixture was continued for $6-8 \mathrm{~h}$ at $120-130^{\circ} \mathrm{C}$. After cooling to r.t., reaction mixture was transferred to the separation funnel using $\mathrm{CH}_{2} \mathrm{Cl}_{2} / 1 \mathrm{M} \mathrm{NaOH}$. The organic layer was washed with $1 \mathrm{M}$ $\mathrm{NaOH}$, water and brine. The organic layer was dried over anhydrous $\mathrm{Na}_{2} \mathrm{SO}_{4}$ and solvent was evaporated under reduced pressure. Crude product was purified using column chromatography.

\section{Procedure B: General procedure for the obtainment of steroidal derivatives 4-11 and $29^{16}$}

Alcohol ( 1 equiv) was dissolved in $\mathrm{CH}_{2} \mathrm{Cl}_{2}$. $\mathrm{PCC}$ ( 1.5 equiv) was added, and the mixture was stirred at r.t. for $3.5 \mathrm{~h}$. Reaction mixture was filtered through a short column of $\mathrm{SiO}_{2}$ (eluent $\mathrm{CH}_{2} \mathrm{Cl}_{2} / \mathrm{EtOAc}=7 / 3$ ). Crude aldehyde was dissolved in dry $\mathrm{MeOH}$, aminoquinoline (1.5 equiv) was added, and mixture was stirred at r.t. overnight. $\mathrm{NaBH}_{4}$ (2 equiv) was added, and stirring was continued at r.t. for $12 \mathrm{~h}$. Solvent was removed under reduced pressure and crude mixture was prepared for column purification.

\section{Procedure C: General procedure for the removal of the Boc-protecting groups with TFA for compounds $14-23$ and 30}

A solution of the $N$-Boc protected amine in TFA/ $\mathrm{CH}_{2} \mathrm{Cl}_{2}$ (v:v; $\left.1: 10\right)$, was stirred at r.t. for 6 h. Solvents were evaporated under reduced pressure and the residue was treated with $\mathrm{CH}_{2} \mathrm{Cl}_{2} / 2.5 \mathrm{M} \mathrm{NaOH}$. The organic layer was dried over $\mathrm{MgSO}_{4}$, and the solvent was evaporated under reduced pressure.

Procedure D: General procedure for N-methylated aminoquinolines 12, 13, 37, 38, 48, $56-65,68,69$ and $84,85^{46}$

To a stirred solution of aminoquinolines (1 equiv) in $\mathrm{MeOH}$ containing $37 \%$ aqueous formaldehyde ( 2 equiv), the mixture of $\mathrm{ZnCl}_{2}$ (2 equiv) and $\mathrm{NaHB}_{3} \mathrm{CN}$ (4 equiv) in $\mathrm{MeOH}$ was added. After the reaction mixture was stirred at r.t. for $4 \mathrm{~h}$, the solution was taken up in $0.1 \mathrm{M} \mathrm{NaOH}$ and most of $\mathrm{MeOH}$ was evaporated under reduced pressure. Aqueous solution was extracted with $\mathrm{CH}_{2} \mathrm{Cl}_{2}$, the combined extracts were washed with water and brine and dried over anhydrous $\mathrm{Na}_{2} \mathrm{SO}_{4}$. The solvent was evaporated under reduced pressure.

Procedure E: General procedure for reductive amination to produce compounds 33,34 , 42-45, 50, 66 and 67

Amine (1.5 equiv) and appropriate aldehyde (1 equiv) were dissolved in $\mathrm{MeOH} / \mathrm{CH}_{2} \mathrm{Cl}_{2}$ mixture (v:v; 2:1), glac. AcOH (1.5 equiv) was added, and the mixture was stirred under $\mathrm{Ar}$ atmosphere at r.t. After $3 \mathrm{~h}, \mathrm{NaBH}_{4}$ ( 6 equiv) was added, and stirring was continued for another $18 \mathrm{~h}$. Solvent was removed under reduced pressure, and the residue was dissolved in $\mathrm{CH}_{2} \mathrm{Cl}_{2}$. The organic layer was washed with $2 \mathrm{M} \mathrm{NH}_{4} \mathrm{OH}$, water and then extracted with $\mathrm{CH}_{2} \mathrm{Cl}_{2}$. The combined organic layers were washed with brine and dried over anh. $\mathrm{Na}_{2} \mathrm{SO}_{4}$. Finally, the solvent was evaporeted under reduced pressure. 


\section{Procedure F: General procedure for the Suzuki coupling reaction using $\mathrm{PdO} \times 1.4 \mathrm{H}_{2} \mathrm{O}$ for compounds 40 and 113.47}

An appropriate aryl bromide ( 1 equiv) was added to the mixture of arylboronic acid (1.2 equiv), catalyst $\mathrm{PdO} \times 1.4 \mathrm{H}_{2} \mathrm{O}$ (0.1 equiv), $\mathrm{K}_{2} \mathrm{CO}_{3}$ (1.2 equiv) and $\mathrm{EtOH} / \mathrm{H}_{2} \mathrm{O}(3: 1$, v/v). The mixture was stirred at $60{ }^{\circ} \mathrm{C}$ for $5 \mathrm{~h}$, then diluted with water and extracted with $\mathrm{CH}_{2} \mathrm{Cl}_{2}$. Combined organic layers were washed with brine and dried over anh. $\mathrm{Na}_{2} \mathrm{SO}_{4}$. After filtration, the solvent was removed under reduced pressure. The product was purified using silica gel flash chromatography.

\section{Procedure G: General procedure for the Suzuki coupling reaction using $\operatorname{Pd}(\mathrm{OAc})_{2}$ and $\mathrm{PPh}_{3}$ for compounds 49 and 111}

The solution of $\mathrm{Pd}(\mathrm{OAc})_{2}$ (0.1 equiv) and $\mathrm{PPh}_{3}$ (0.4 equiv) in DME was purged with argon and stirred at $\mathrm{r}$. t. for $10 \mathrm{~min}$. An appropriate arylboronic acid (1 equiv) and $2 \mathrm{M}$ aq. $\mathrm{Na}_{2} \mathrm{CO}_{3}$ were added. After 5 min, aryl-bromide (1 equiv) was added. The mixture is once more purged with $\mathrm{Ar}$ and heated in a sealed vessel in microwave reactor at $80{ }^{\circ} \mathrm{C}$ for $3 \mathrm{~h}$. The reaction mixture was cooled and extracted with ethyl-acetate. The combined organic layers were washed with brine and dried over anh. $\mathrm{Na}_{2} \mathrm{SO}_{4}$. After filtration, the solvent was removed under reduced pressure. The crude product was further purified in a manner provided for each compound.

\section{Procedure H: General procedure for palladium catalyzed amination of quinolines to produce compounds $78,79,81$ and 82}

Vial was charged with mixture of $\mathrm{Pd}(\mathrm{OAc})_{2}(4 \mathrm{~mol} \%)$ and DPEphos $(8 \mathrm{~mol} \%) / \mathrm{SPhos}(8$ $\mathrm{mol} \%)$ in dioxne and stirred for a few minutes in $\mathrm{Ar}$ atmosphere on room temperature. Subsequently, haloquinoline (1.0 equiv), amine (1.2 equiv) and $\mathrm{K}_{3} \mathrm{PO}_{4}$ (2.5 equiv) were added in to reaction mixture. The resulting suspension was sparged with argon for several minuties. The vial was quickly capped, heated to $85^{\circ} \mathrm{C}$ over the night and then cooled down to room temperature. The mixture was adsorbed onto silica gel and purified.

$N$-(quinolin-4 yl)ethane-1,2-diamine (AQ11), $N$-(7-chloroquinolin-4-yl)butane-1,4-diamine (AQ4), $N$-(7-chloroquinolin-4-yl)hexane-1,6-diamine (AQ6), $N$-(quinolin-4-yl)propane-1,3diamine (AQ7), $N$-(quinolin-4-yl)butane-1,4-diamine (AQ8), $N$-(quinolin-4-yl)hexane-1,6diamine (AQ9), $N$-quinolin-4 yldecane-1,10-diamine (AQ12) were prepared according to known procedures. ${ }^{48-51}$

\section{In vitro HPLC-based Proteolytic Assay for BoNT/A LC Inhibition}

BoNT/A LC 17-mer HPLC endpoint assay in 96well plate (manual method) uses $2.5 \mathrm{mM}$ stock solution of the 17-mer peptide (termed P39, acetyl-SNKTRIDEANQRATKML-amide) in $50 \mathrm{mM}$ HEPES, $\mathrm{pH} 7.4$ For the inhibitor, the final concentration was $20 \mu \mathrm{M}$, diluted from a working stock of $120 \mu \mathrm{M}$ in $50 \mathrm{~m}$ M HEPES $\mathrm{pH}$ 7.4. Just prior to conducting the assay, LcA was diluted to $0.1 \mathrm{mg} / \mathrm{mL}$ in $50 \mathrm{mM}$ HEPES pH 7.4 and kept on ice. Final concentrations for the assay are as follows: $[\mathrm{LcA}]=1.95 \mu \mathrm{g} / \mathrm{mL}(20 \mathrm{nM}),[\mathrm{BSA}]=0.2$ $\mathrm{mg} / \mathrm{mL},[\mathrm{P} 39]=$ final conc $0.25 \mathrm{mM}$, [Inhibitor] $=20 \mu \mathrm{M}$ in a total reaction volume of 30 $\mu \mathrm{L}$. The assay is conducted as follows. The compound ( $5 \mu \mathrm{l}$ of the $120 \mu \mathrm{M}$ working stock) is 
incubated with the LcA master mix (LcA and BSA in 50mM HEPES) and incubated for 10 minutes at room temperature. The P39 substrate is then added and the samples are incubated at $37^{\circ} \mathrm{C}$ for 10 minutes. Cleavage products of the P39 substrate are monitored and quantitated using a Shimadzu Prominence ultra fast liquid chromatography (UFLC) XR system using a Hypersil Gold Javelin (Thermo Fisher Scientific, Waltham, MA) c18 guard column and a Hypersil Gold (Thermo Fisher Scientific, Waltham, MA) c18 reverse-phase analytical column $(50 \times 2.1 \mathrm{~mm}, 1.9 \mu \mathrm{m})$. Flow rate of $1.000 \mathrm{ml} / \mathrm{min}$. Column chamber oven temp $65^{\circ} \mathrm{C}$. Monitor absorbance at $214 \mathrm{~nm}$ and $280 \mathrm{~nm}$. The solvents and gradient are as follows: Buffer A $=$ HPLC grade water $+0.05 \%$ Trifluoroacetic acid; Buffer $\mathrm{B}=50 \%$ HPLC grade Acentonitrile $+0.05 \%$ Trifluoroacetic acid. All HPLC separations were conducted and peak areas measured with the LC solution automated integration software (Shimadzu Corporation, Kyoto, Japan). For BoNT/A, the fragment peaks retention times were $\approx(0.9-$ $1.1 \mathrm{~min})$ and (1.3-1.5 min). Percent inhibition of each compound tested was calculated using the following formula: $100-(\Sigma$ of fragment peak areas + compound $/ \Sigma$ of fragment peak areas - compound) $\times 100$.

\section{Derivation of motor neurons from mouse embryonic stem cells}

We have utilized a specific mouse embryonic stem (ES) cell (HBG3) line, in which mouse motor neuron specific $\mathrm{Hb} 9$ promotor drives eGFP expression, to generate motor neurons. The specifics regarding the culture, differentiation and maintenance of these cells, and the characterization of derived motor neurons have been published. ${ }^{52,53}$

\section{BoNT intoxication, Inhibitor Application and Western blot analysis for the BoNT mediated SNAP-25 cleavage determination}

For pre intoxication studies, the motor neurons differentiated from mouse ES cells were cultured in 24-well plates and treated with the indicated amounts of compounds in the figures. Following a 30 min incubation, the cultures were intoxicated with $500 \mathrm{pM}$ BoNT/A (MetaBiologics, Madison, WI). For post intoxication studies, the cultures were first intoxicated with 500pM BoNT/A and then the compounds were applied to the plates 30 or $60 \mathrm{~min}$ after the intoxication. In both pre and post intoxication models, total intoxication time was kept constant as 4 hours and the neurons were maintained at $37^{\circ} \mathrm{C}$ cell culture humidified incubators with $5 \% \mathrm{CO}_{2}$ atmosphere. The cells were then washed with PBS thoroughly, and lysed in NP-40 cell lysis buffer. The extent of SNAP-25 cleavage was quantified using standard immunoblotting procedures with SNAP-25 antibodies that detect both the full length and the BoNT/A cleaved large fragment, as described previously. ${ }^{7,10}$ Briefly, the cell lysates were processed, run on $12 \%$ Tris Glycine gels (Invitrogen, \#XP00125), and transferred to nitrocellulose membranes. Membranes were blocked in 5\% non-fat milk for $1 \mathrm{hr}$, and then incubated with primary antibodies against GAPDH (Millipore, \#MAB374), and SNAP-25 (BioLegend, SMI-81, \#836304) in TBST buffer containing 5\% milk overnight at $4{ }^{\circ} \mathrm{C}$. Horse radish peroxidase conjugated secondary antibodies (Millipore) were utilized for the detection of the signal. The blots were visualized with Pierce ECL Western detection kit, using a gel documentation and analysis system. 


\section{$\log D$ (shake-flask) metod}

Standard shake-flask method was used for $\log D$ (pH 7.31, $30 \mathrm{mM}$ TBS) determination. ${ }^{37-39}$

Stock solution of 16 was prepared in octanol $\left(c=2.5 \times 10^{-3} \mathrm{M}\right)$.

\section{Toxicity studies: in vivo}

Groups of five healthy mice were treated per os (p.o.) for three consecutive days with aminoquinolines suspended in $0.5 \%$ hydroxyethylcellulose $-0.1 \%$ Tween 80 , previously dissolved in DMSO. Individual mouse behavior and appearance was monitored two times a day for 30 days. Compounds proved to be non-toxic if all 5 mice survived 30 days after administration and showed normal appearance and behavior.

The study followed the International Guiding Principles for biomedical research involving animals, and was reviewed by a local Ethics Committee and approved by the Veterinary Directorate at the Ministry of Agriculture and Environmental Protection of Serbia (decision no. 32307 02444/2014 05/1).

\section{In vitro Plasma Protein Binding (Equilibrium dialysis for 16)}

In vitro plasma protein binding was performed by the ADME Center at USAMRICD using Thermo Scientific's protocol and their Single-Use RED (rapid equilibrium dialysis) Plates. Samples $(100-500 \mu \mathrm{L})$ were prepared by spiking test compound with plasma at the appropriate concentrations and places into the sample chamber. Dialysis buffer (300-750 $\mu \mathrm{L}$ ) was added to the buffer chamber. The unit was covered with sealing tape and incubated at $37^{\circ} \mathrm{C}$ on an orbital shaker at approximately $250 \mathrm{rpm}$ or $20 \mathrm{rpm}$ on an up and down shaker for $4 \mathrm{~h} .50 \mu \mathrm{L}$ from both the buffer and the plasma chambers were placed in separate microcentrifuge tubes or into a deep well plate for analysis. $50 \mu \mathrm{L}$ of plasma was added to the buffer sample and an equal volume of buffer to the collected plasma sample. $300 \mu \mathrm{L}$ of Internal Standard containing precipitation buffer (such as cold 90/10 acetonitrile/water with $0.1 \%$ formic acid) was added to precipitate protein and release compound. Vortexed and incubated 30 minutes on ice, centrifuged for 10 minutes at 13,000-15,000 $\times g$. The supernatant was analyzed with LC-MS/MS. The test compound concentration in the buffer and plasma chambers were determined from peak areas relative to the internal standard. The percentage of the test compound bound was calculated as follows: $\%$ Free $=($ Concentration buffer chamber/Concentration plasma chamber $) \times 100 \%$. $\%$ Bound $=100 \%-\%$ Free.

\section{In vitro Plasma Protein Binding (Spectrofluorimetric determination for compound 16)}

Human serum albumin (HSA), alpha-1-acid glycoprotein (AGP), potassium dihydrogen phosphate, disodium hydrogen phosphate, sodium chloride, potassium chloride and DMSO were purchased from Sigma-Aldrich. Fluorescence spectra were recorded on Horiba Jobin Yvon Fluoromax-4 spectrometer, equipped with Peltier element and magnetic stirrer for cuvette, using quartz cell with $1 \mathrm{~cm}$ path length and $4 \mathrm{~mL}$ volume. UV-Vis spectra were recorded on Thermo scientific spectrophotometer evolution 60s using quartz cell with $1 \mathrm{~cm}$ path length and $4 \mathrm{~mL}$ volume. All UV/Vis spectra were recorded against the corresponding blank in the 200-500 nm wavelength range, with $500 \mathrm{~nm} / \mathrm{min}$ scan speed. $\mathrm{pH}$ Values were potentiometrically measured using Crison $\mathrm{pH}-\mathrm{Burette} 242 \mathrm{~S}$ equipped with a micro- 
combined $\mathrm{pH}$ electrode (Crison $\mathrm{pH}$ electrode 5029 ). The $\mathrm{pH}$ electrode was calibrated by standard Crison buffer solutions ( $\mathrm{pH} 4.01,7.00$, and 9.21). Stock solutions of AGP ( $c=6.05$ $\left.\times 10^{-5} \mathrm{M}\right)$ and HSA $\left(c=1.91 \cdot 10^{-4} \mathrm{M}\right)$ were prepared in PBS (1X, pH 7.34) and kept in the refrigerator. Stock solution of $\mathbf{1 6}\left(c=4.28 \times 10^{-4} \mathrm{M}\right)$ was prepared in DMSO. For protein-16 interaction studies, protein solutions were freshly prepared from the stock, by dilution with a buffer (AGP and HSA concentration was kept constant, $c=5 \cdot \times 10^{-7} \mathrm{M}$ ), and titrated with compound stock solution (from 1 to 20 compound/protein molar ratio). During the titration, the solutions were stirred and thermostated $\left(t=25.0 \pm 0.1^{\circ} \mathrm{C}\right.$, regulated by Peltier element). The equilibration time between increment additions was 10 minutes. An excitation wavelength was $280 \mathrm{~nm}$, with $5 \mathrm{~nm}$ slits; emission spectra were recorded in 300-450 nm wavelength range, with $5 \mathrm{~nm}$ slits, and $0.1 \mathrm{~s}$ integration time. Background PBS signal was subtracted from each spectrum. Fluorescence intensities were corrected for inner filter effect by measuring absorbances at excitation and emission wavelength.

\section{In vivo Mouse Pharmacokinetics}

Compound 16 was dissolved in DMSO, suspended in $0.5 \%$ hydroxyethylcellulose $-0.1 \%$ Tween 80 in water and administered orally at two different concentrations. Blood was collected from one mouse, previously anaesthetized with chloroform, for each time point via cardiac puncture. Samples were immediately centrifuged and serum stored at $-20{ }^{\circ} \mathrm{C}$ until the moment of analysis. Human serum was collected from a healthy volunteer and stored in refrigerator at $4{ }^{\circ} \mathrm{C}$. Total concentrations of compound in mice samples were determined by precipitation of proteins by addition of two volume equivalents of acetonitrile $(50 \mu \mathrm{L}$ of sample and $100 \mu \mathrm{L}$ of acetonitrile), following 15 seconds on vortex and 30 minutes in ultrasound bath. After centrifugation of denatured proteins (10 minutes, $13400 \mathrm{rpm}$ ), supernatants were injected. For determination of free concentration, ultracentrifugation method was used. $150 \mu \mathrm{L}$ of mice samples were centrifuged on Beckman Coulter ultracentrifuge (rotor type SW55 Ti, $25000 \mathrm{rpm}, 24 \mathrm{~h}, 4{ }^{\circ} \mathrm{C}, 0.8 \mathrm{~mL}$ tubes). Mice serum has been separated into three layers, $30 \mu \mathrm{L}$ of transparent middle layer was taken from each tube via syringe and injected into UPLC-MS/MS. Transparent middle layer showed $1 \%$ of starting plasma proteins, as confirmed by BCA method for determination of concentration of proteins. Calibration curves for free and total concentrations were prepared using blank human serum. In case of total concentration, compound standard solutions were prepared in DMSO (250 and $2500 \mu \mathrm{g} / \mathrm{mL}$ ). Human serum was spiked with stock solutions, final solutions $(1-25 \mu \mathrm{g} / \mathrm{mL})$ were incubated at $37{ }^{\circ} \mathrm{C}$ for $1 \mathrm{~h}$ and treated with acetonitrile in the same way. For determination of free concentration of the drug, ultracentrifugation method was used. Standard solutions of compound $(0.5-10 \mu \mathrm{g} / \mathrm{mL})$ were prepared in supernatants obtained by ultracentrifugation of blank human serum. From both experiments, 15-45 min samples were centrifuged on Beckman Coulter ultracentrifuge (rotor type SW55 Ti, 24 h, $4{ }^{\circ} \mathrm{C}, 25000 \mathrm{rpm}, 0.8 \mathrm{~mL}$ tubes) and analyzed for compound $\mathbf{1 6}$. Concentrations of compound in mice serum were quantitated using a Waters Acquity UPLC H-Class (WAT-176015007) (Milford, MA, USA) with Poroshell 120 EC-C18 column $(4.6 \times 50 \mathrm{~mm}$, 2.7 $\mu$, S.N. USCFU07797) and interfaced to mass detector (Waters TQ (Tandem Quadrupole, WAT-176001263)). Single ion recording experiment (SIR) was used, by monitoring three ions: $[\mathrm{M}+\mathrm{H}]^{1+}(709),[\mathrm{M}+2 \mathrm{H}]^{2+}(355)$ and $[\mathrm{M}+3 \mathrm{H}]^{3+}(237)$. Column temperature was maintained at $40{ }^{\circ} \mathrm{C}$ and mobile phase flow rate at $0.3 \mathrm{~mL} / \mathrm{min}$. The mobile phase consisted 
of ultrapure water (TKA Germany MicroPure water purification system, $0.055 \mu \mathrm{S} / \mathrm{cm}$ ) containing 0.2 vol.\% formic acid (solvent A) and acetonitrile (solvent B), with a gradient 0$2 \min 5 \% \mathrm{~B}, 2-8 \min 5 \% \mathrm{~B} \rightarrow 95 \% \mathrm{~B}, 8-12 \min 95 \% \mathrm{~B}, 12-12.5 \min 95 \% \mathrm{~B} \rightarrow 5 \% \mathrm{~B}, 12.5-15$ $\min 5 \% \mathrm{~B}$ for reconditioning of the column. Injection volume was $10 \mu \mathrm{L}$. For detection of total concentration, limit of detection (LOD) was $1 \mu \mathrm{g} / \mathrm{mL}(\mathrm{S} / \mathrm{N}>3: 1)$, limit of quantitation (LOQ) was $2 \mu \mathrm{g} / \mathrm{mL}(\mathrm{S} / \mathrm{N} \geq 10: 1)$ and $R^{2}=0.9952$ (calibration curve was performed in triplicate).

\title{
Supplementary Material
}

Refer to Web version on PubMed Central for supplementary material.

\section{Acknowledgments}

This research was supported by the National Institute of Allergy and Infectious Diseases (U.S.) Grant 5U01AI082051-02 (SB, BS, AJD, LHC) and R33-AI101387 (EK, KK, JKT), and by the Ministry of Science and Technological Development of Serbia Grant 172008 (JK, MV, NTJ, TZV, BS), Serbian Academy of Sciences and Arts (BS), and the U.S. Defense Threat Reduction Agency/Joint Science and Technology Office (SB). We thank Dr. Olgica Djurković-Djaković and MSc Jelena Srbljanović (Institute for Medical Research, University of Belgrade) for help and collaboration with collecting mice blood samples for pharmacokinetics and performing in vivo toxicity studies; MSc Jovana Periša (Vinča Institute of Nuclear Sciences, University of Belgrade) for assistance with synthesis of adamantane derivatives; Dr. Milka Jadranin (Institute of Chemistry, Technology and Metallurgy, University of Belgrade) for optimization of UPLC-MS/MS method and Dr. Milan Kojić (Institute of Molecular Genetics and Genetic Engineering, University of Belgrade) for optimization of ultracentrifuge method used for the analysis of mice samples. We also thank Dr. Sandra Šegan (Institute of Chemistry, Technology and Metallurgy, University of Belgrade) for carrying out $\log D$ experiments using reversed-phase thin-layer chromatography. We thank Dr. Benedict Capacio and colleagues at the ADME Center at the US Army Medical Institute for Chemical Defense for evaluating the ADME properties of compound 16. B.S. thanks prof. Mario Zlatović, Faculty of Chemistry, University of Belgrade, for performing docking simulations presented in Supporting Information section.

\section{ABBREVIATIONS}

\author{
ABS $252 N$-(3-(4-fluorophenyl)-1H pyrazol-5 yl)-2-mercaptoacetamide \\ Dyngo-4a 3-hydroxy- $N^{\prime}$-[(1E)-(2,4,5-trihydroxyphenyl)methylene]-2 \\ naphthohydrazide \\ EGA 4-bromobenzaldehyde-N-(2,6-dimethylphenyl)semicarbazone \\ BoNT/A LC botulinum neurotoxin serotype A light chain \\ mES-MNs mouse embryonic stem cell derived motor neurons \\ SNAP-25 synaptosomal-associated protein 25 \\ SNARE soluble $N$-ethylmaleimide-sensitive fusion attachment protein receptor \\ SMNPI small molecule non-peptidic inhibitors \\ AQn $\quad N$-(7-chloroquinolin-4-yl)alkane-1,n-diamine or $N$-quinolin-4-ylalkane-1,n- \\ diamine
}

MDR1-MDCKadin Darby canine kidney (MDCK) cells with the MDR1 gene 


\section{References}

1. Montecucco C, Molgo J. Botulinal neurotoxins: revival of an old killer. Curr Opin Pharmacol. 2005; 5:274-279. [PubMed: 15907915]

2. Agarwal R, Swaminathan S. SNAP-25 substrate peptide (residues 180-183) binds to but bypasses cleavage by catalytically active Clostridium botulinum neurotoxin E. J Biol Chem. 2008; 283:25944-25951. [PubMed: 18658150]

3. Barash JR, Arnon SS. A novel strain of Clostridium botulinum that produces type B and type H botulinum toxins. J Infect Dis. 2013; 209:183-191. [PubMed: 24106296]

4. Duplantier AJ, Kane CD, Bavari S. Searching for therapeutics against botulinum neurotoxins: a true challenge for drug discovery. Curr Top Med Chem. 2016; 16:2330-2349. [PubMed: 27072693]

5. Rossetto O, Pirazzini M, Montecucco C. Botulinum neurotoxins: Genetic, structural and mechanistic insights. Nature Rev Microbiol. 2014; 12:535-549. [PubMed: 24975322]

6. Pirazzini M, Rossetto O. Challenges in searching for therapeutics against botulinum neurotoxins. Expert Opin Drug Discov. 2017; 12:497-510. [PubMed: 28271909]

7. Kiris E, Burnett JC, Nuss JE, Wanner LM, Peyser BD, Du HT, Gomba GY, Kota KP, Panchal RG, Gussio R, Kane CD, Tessarollo L, Bavari S. Src family kinase inhibitors antagonize the toxicity of multiple serotypes of botulinum neurotoxin in human embryonic stem cell-derived motor neurons. Neurotox Res. 2015; 27:384-398. [PubMed: 25782580]

8. Pirazzini M, Azarnia TD, Zanetti G, Megighian A, Scorzeto M, Fillo S, Shone CC, Binz T, Rossetto $\mathrm{O}$, Lista F, Montecucco C. Thioredoxin and its reductase are present on synaptic vesicles, and their inhibition prevents the paralysis induced by botulinum neurotoxins. Cell Rep. 2014; 8:1870-1878. [PubMed: 25220457]

9. Seki H, Xue S, Pellett S, Šilhár P, Johnson EA, Janda KD. Cellular protection of SNAP 25 against botulinum neurotoxin/A: inhibition of thioredoxin reductase through a suicide substrate mechanism. J Am Chem Soc. 2016; 138:5568-5575. [PubMed: 27070533]

10. Kiris E, Nuss JE, Stanford SM, Wanner LM, Cazares L, Maestre MF, Du HT, Gomba GY, Burnett JC, Gussio R, Bottini N, Panchal RG, Kane CD, Tessarollo L, Bavari S. Phosphatase inhibitors function as novel, broad spectrum botulinum neurotoxin antagonists in mouse and human embryonic stem cell-derived motor neuron-based assays. PLoS ONE. 2015; 10:e0129264. [PubMed: 26061731]

11. Boldt GE, Kennedy JP, Janda KD. Identification of a potent botulinum neurotoxin A protease inhibitor using in situ lead identification chemistry. Org Lett. 2006; 8:1729-1732. [PubMed: 16597152]

12. Burnett JC, Schmidt JJ, Stafford RG, Panchal RG, Nguyen TL, Hermone AR, Vennerstrom JL, McGrath CF, Lane DJ, Sausville EA, Zaharevitz DW, Gussio R, Bavari S. Novel small molecule inhibitors of botulinum neurotoxin A metalloprotease activity. Biochem Biophys Res Commun. 2003; 310:84-93. [PubMed: 14511652]

13. Šolaja BA, Opsenica D, Smith KS, Milhous WK, Terzic N, Opsenica I, Burnett JC, Nuss J, Gussio $\mathrm{R}$, Bavari S. Novel 4-aminoquinolines active against chloroquine-resistant and sensitive $\mathrm{P}$. falciparum strains that also inhibit botulinum serotype A. J Med Chem. 2008; 51:4388-4391. [PubMed: 18637666]

14. Opsenica I, Filipovic V, Nuss JE, Gomba LM, Opsenica D, Burnett JC, Gussio R, Šolaja BA, Bavari S. The synthesis of 2,5-bis(4-amidinophenyl)thiophene derivatives providing submicromolar-range inhibition of the botulinum neurotoxin serotype A metalloprotease. Eur J Med Chem. 2012; 53:374-379. [PubMed: 22516424]

15. Burnett JC, Opsenica D, Sriraghavan K, Panchal RG, Ruthel G, Hermone AR, Nguyen TL, Kenny TA, Lane DJ, McGrath CF, Schmidt JJ, Vennerstrom JL, Gussio R, Šolaja BA, Bavari S. A refined pharmacophore identifies potent 4-amino-7-chloroquinoline-based inhibitors of the botulinum neurotoxin serotype A metalloprotease. J Med Chem. 2007; 50:2127-2136. [PubMed: 17417831]

16. Videnović M, Opsenica DM, Burnett JC, Gomba L, Nuss JE, Selaković Ž, Konstantinović J, Krstić M, Šegan S, Zlatović M, Sciotti RJ, Bavari S, Šolaja BA. Second generation steroidal 4aminoquionolines are potent, dual-target inhibitors of the botulinum neurotoxin serotype A 
metalloprotease and P. falciparum malaria. J Med Chem. 2014; 57:4134-4153. [PubMed: 24742203]

17. Pellett S. Progress in cell based assays for botulinum neurotoxin detection. Curr Top Microbiol Immunol. 2013; 364:257-285. [PubMed: 23239357]

18. Stahl AM, Ruthel G, Torres-Melendez E, Kenny TA, Panchal RG, Bavari S. Primary cultures of embryonic chicken neurons for sensitive cell-based assay of botulinum neurotoxin: implications for therapeutic discovery. J Biomol Screen. 2007; 12:370-377. [PubMed: 17332092]

19. Keller JE, Neale EA, Oyler G, Adler M. Persistence of botulinum neurotoxin action in cultured spinal cord cells. FEBS Lett. 1999; 456:137, 142. [PubMed: 10452545]

20. Pellett S, Tepp WH, Clancy CM, Borodic GE, Johnson EA. A neuronal cell-based botulinum neurotoxin assay for highly sensitive and specific detection of neutralizing serum antibodies. FEBS Lett. 2007; 581:4803-4808. [PubMed: 17889852]

21. Kiris E, Kota KP, Burnett JC, Soloveva V, Kane CD, Bavari S. Recent developments in cell-based assays and stem cell technologies for botulinum neurotoxin research and drug discovery. Expert Rev Mol Diagn. 2014; 14:153-168. [PubMed: 24450833]

22. Bremer PT, Adler M, Phung CH, Singh AK, Janda KD. Newly designed quinolinol inhibitors mitigate the effects of botulinum neurotoxin A in enzymatic, cell-based, and ex vivo assays. J Med Chem. 2017; 60:338-348. [PubMed: 27966961]

23. Tehran DA, Zanetti G, Leka O, Lista F, Fillo S, Binz T, Shone CC, Rossetto O, Montecucco C, Paradisi C, Mattarei A, Pirazzini M. A novel inhibitor prevents the peripheral neuroparalysis of botulinum neurotoxins. Sci Rep. 2015; 5:17513. [PubMed: 26670952]

24. Eubanks LM, Hixon MS, Jin W, Hong S, Clancy CM, Tepp WH, Baldwin MR, Malizio CJ, Goodnough MC, Barbieri JT, Johnson EA, Boger DL, Dickerson TJ, Janda KD. An in vitro and in vivo disconnect uncovered through high-throughput identification of botulinum neurotoxin A antagonists. PNAS. 2007; 104:2602-2607. [PubMed: 17293454]

25. Thyagarajan B, Potian JG, Garcia CC, Hognason K, Capkova K, Moe ST, Jacobson AR, Janda KD, McArdle JJ. Effects of hydroxamate metalloendoprotease inhibitors on botulinum neurotoxin A poisoned mouse neuromuscular junctions. Neuropharmacology. 2010; 58:1189-1198. [PubMed: 20211192]

26. Pang YP, Davis J, Wang S, Park JG, Nambiar MP, Schmidt JJ, Millard CB. Small molecules showing significant protection of mice against botulinum neurotoxin serotype A. PloS ONE. 2010; 5:e10129. [PubMed: 20405003]

27. Eichhorn T, Dolimbek BZ, Deeg K, Efferth T, Atassi MZ. Inhibition in vivo of the activity of botulinum neurotoxin A by small molecules selected by virtual screening. Toxicon. 2012; 60:1180-1190. [PubMed: 22960451]

28. Bremer PT, Pellett S, Carolan JP, Tepp WH, Eubanks LM, Allen KN, Johnson EA, Janda KD. Metal ions effectively ablate the action of botulinum neurotoxin A. J Am Chem Soc. 2017; 139:7264-7272. [PubMed: 28475321]

29. Jacobson AR, Adler M, Silvaggi NR, Allen KN, Smith GM, Fredenburg RA, Stein RL, Park J-B, Feng X, Shoemaker CB, Deshpande SS, Goodnough MC, Malizio CJ, Johnson EA, Pellett S, Tepp WH, Tzipori S. Small molecule metalloprotease inhibitor with in vitro, ex vivo and in vivo efficacy against botulinum neurotoxin serotype A. Toxicon. 2017; 137:36-47. [PubMed: 28698055]

30. Seki H, Xue S, Hixon MS, Pellet S, Remes M, Johnson EA, Janda KD. Toward the discovery of dual inhibitors of botulinum neurotoxin A: concomitant targeting of endocytosis and light chain protease activity. Chem Commun. 2015; 51:6226-6229.

31. Konstantinović J, Videnović M, Srbljanović J, Djurković-Djaković O, Bogojević K, Sciotti R, Šolaja B. Antimalarials with benzothiophene moieties as aminoquinoline partners. Molecules. 2017; 22:343.

32. Terzić N, Konstantinović J, Tot M, Burojević J, Djurković-Djaković O, Srbljanović J, Štajner T, Verbić T, Zlatović M, Machado M, Albuquerque IS, Prudêncio M, Sciotti RJ, Pecic S, D’Alessandro S, Taramelli D, Šolaja BA. Reinvestigating old pharmacophores: are 4aminoquinolines and tetraoxanes potential two-stage antimalarials? J Med Chem. 2016; 59:264 281. [PubMed: 26640981] 
33. Marković OS, Cvijetić IN, Zlatović MV, Opsenica IM, Konstantinović JM, Terzić Jovanović NV, Šolaja BA, Verbić TŽ. Human serum albumin binding of certain antimalarials. Spectrochim Acta Mol Biomol Spectrosc. 2018; 192:128-139.

34. Aleksić I, Šegan S, Andrić F, Zlatović M, Moric I, Opsenica DM, Senerovic L. Long-chain 4aminoquinolines as quorum sensing inhibitors in Serratia marcescens and Pseudomonas aeruginosa. ACS Chem Biol. 2017; 12:1425-1434. [PubMed: 28350449]

35. Nuss JE, Wanner LM, Tressler LE, Bavari S. The osmolyte trimethylamine N-oxide (TMAO) increases the proteolytic activity of botulinum neurotoxin light chains A, B, and E: implications for enhancing analytical assay sensitivity. J Biomol Screen. 2010; 15:928-936. [PubMed: 20720092]

36. Sobanska AW, Wójcicka K, Brzezinska E. Evaluation of the lipophilicity of selected sunscreens - a chemometric analysis of thin-layer chromatographic retention data. J Sep Sci. 2014; 37:30743081. [PubMed: 25146246]

37. Takács-Novák K, Avdeel A. Interlaboratory study of $\log P$ determination by shake-flask and potentiometric methods. J Pharm Biomed Anal. 1996; 14:1405-1413. [PubMed: 8877846]

38. EPA 712-C-96-038, Product Properties Test Guidelines, OPPTS 830.7550: Partition coefficient (noctanol/water), shake flask method. U.S. Environmental Protection Agency; Washington D.C.: 1996.

39. Test No. 107: Partition Coefficient (n-octanol/water): Shake Flask Method. OECD; Paris: 1995. OECD Guidelines for the testing of chemicals, Section 1. Physical-chemical properties. http:// dx.doi.org/10.1787/9789264069626-en. Assessed 15 January 2018

40. Department of Defense, ADMET Center at USAMRICD, Gunpowder, Maryland, USA.

41. Di L, Kerns EH. Profiling drug-like properties in discovery research. Curr Opin Chem Biol. 2003; 7:402-408. [PubMed: 12826129]

42. Yamasaki K, Chuang VTG, Maruyama T, Otagiri M. Albumin-drug interaction and its clinical implication. Biochimic Biophys Acta. 2013; 1830:5435-5443.

43. Israili ZH, Dayton PG. Human alpha-1-glycoprotein and its interactions with drugs. Drug Metab Rev. 2001; 33:161-235. [PubMed: 11495502]

44. Smith DA, Di L, Kerns EH. The effect of plasma protein binding on in vivo efficiacy: misconceptions in drug discovery. Nat Rev Drug Discov. 2010; 9:929-939. [PubMed: 21119731]

45. Ruthel G, Burnett JC, Nuss JE, Wanner LM, Tressler LE, Torres-Melendez E, Sandwick SJ, Retterer CJ, Bavari S. Post-intoxication inhibition of botulinum neurotoxin serotype A within neurons by small-molecule, non-peptidic inhibitors. Toxins. 2011; 3:207-217. [PubMed: 22069707]

46. Kim S, Oh CH, Ko JS, Ahn KH, Kim YJ. Zinc-modified cyanoborohydride as a selective reducing agent. J Org Chem. 1985; 50:1927-1932.

47. Amoroso F, Colussi S, Del Zotto A, Llorca Piqué J, Trovarelli A. PdO hydrate as an efficient and recyclable catalyst for the Suzuki-Miyaura reaction in water/ethanol at room temperature. Cat Commun. 2011; 12:563-567.

48. Musonda CC, Gut J, Rosenthal PJ, Yardley V, Carvalho de Souza RC, Chibale K. Application of multicomponent reactions to antimalarial drug discovery. Part 2: New antiplasmodial and antitrypanosomal 4-aminoquinoline $\gamma$ and $\delta$-lactams via a 'catch and release' protocol. Bioorg Med Chem. 2006; 14:5605-5615. [PubMed: 16690319]

49. Peck RM, Preston RK, Creech HJ. Nitrogen mustard analogs of antimalarial drugs. J Am Chem Soc. 1959; 81:3984-3989.

50. Price CC, Leonard NJ, Peel EW, Reitsema RH. Some 4-amino-7-chloroquinoline derivatives. J Am Chem Soc. 1946; 68:1807-1808. [PubMed: 21001098]

51. Singh C, Malik H, Puri SK. Synthesis and antimalarial activity of a new series of trioxaquines. Bioorg Med Chem. 2004; 12:1177-1182. [PubMed: 14980628]

52. Kiris E, Nuss JE, Burnett JC, Kota KP, Koh DC, Wanner LM, Torres-Melendez E, Gussio R, Tessarollo L, Bavari S. Embryonic stem cell-derived motoneurons provide a highly sensitive cell culture model for botulinum neurotoxin studies, with implications for high-throughput drug discovery. Stem Cell Res. 2011; 6:195-205. [PubMed: 21353660] 
53. Wichterle H, Lieberam I, Porter JA, Jessell TM. Directed differentiation of embryonic stem cells into motor neurons. Cell. 2002; 110:385-397. [PubMed: 12176325] 


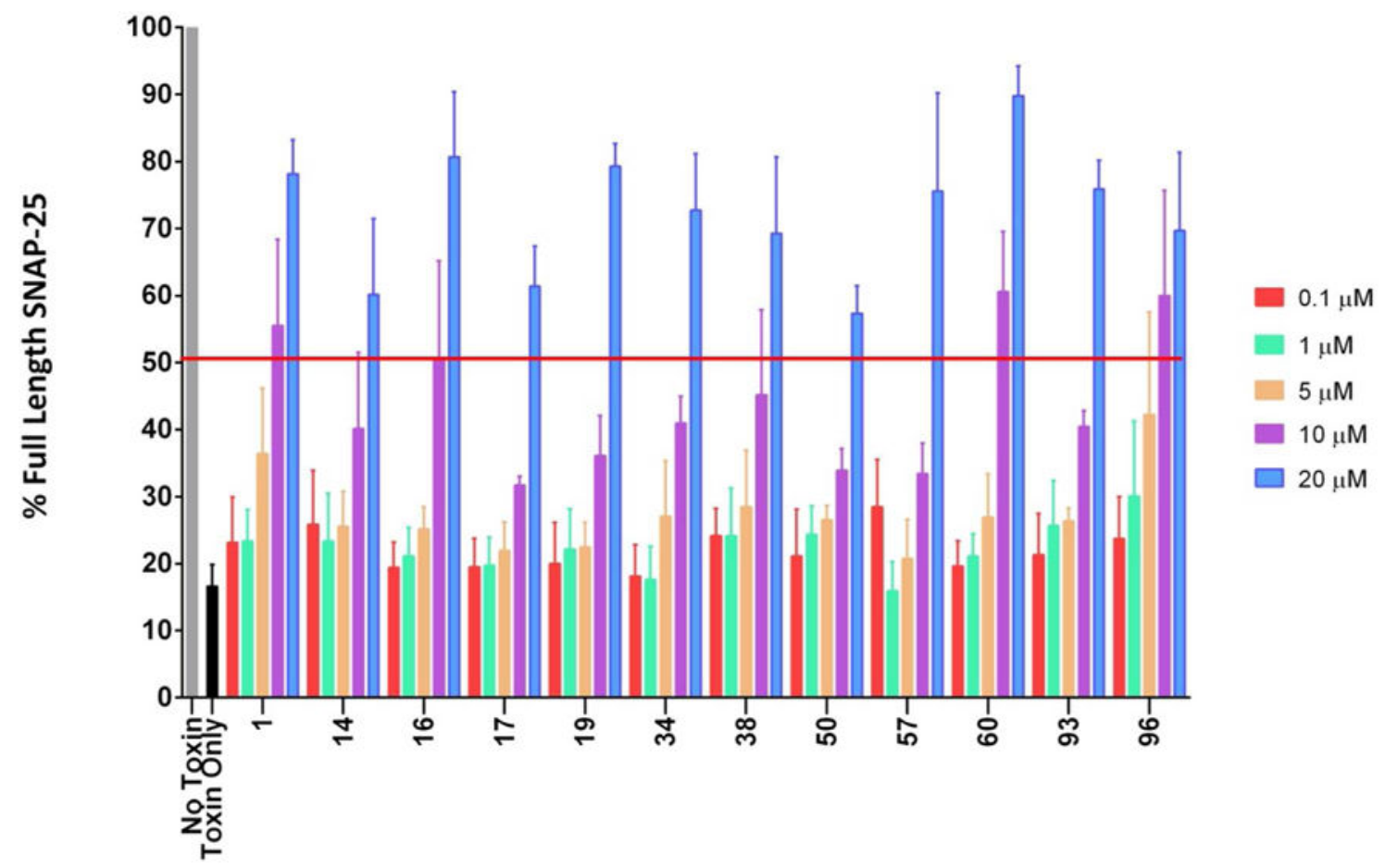

500 pM BoNT/A

Figure 1.

Protection of SNAP-25 in mES-MNs in pre-intoxication model (results are given as mean value of three independent experiments +/- SEM, values given in Table S2). 


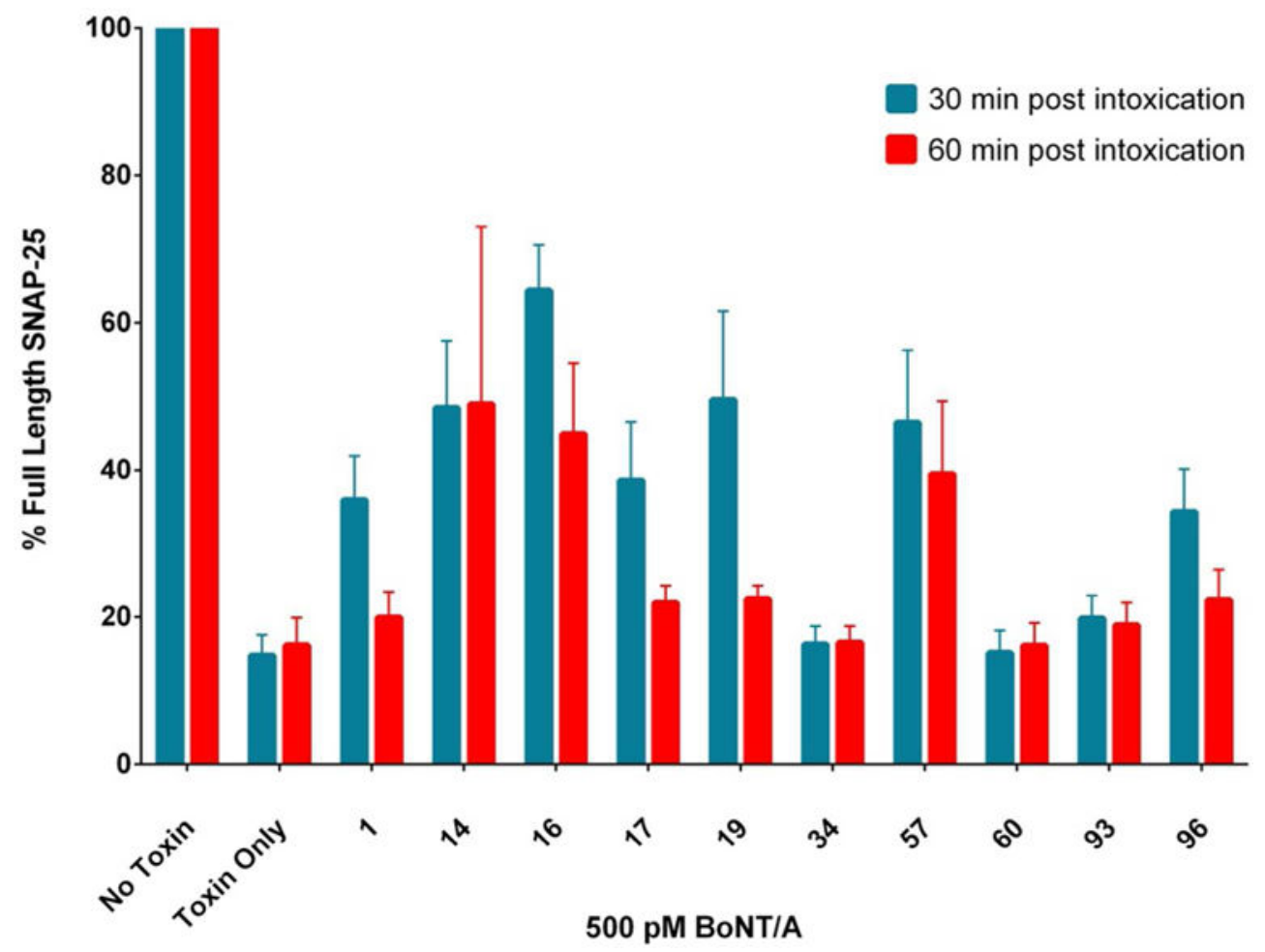

Figure 2.

Protection of SNAP-25 in mES-MNs in post-intoxication model at $20 \mu \mathrm{M}$ (results are given as mean value of three independent experiments +/- SEM, values given in Table S3). 


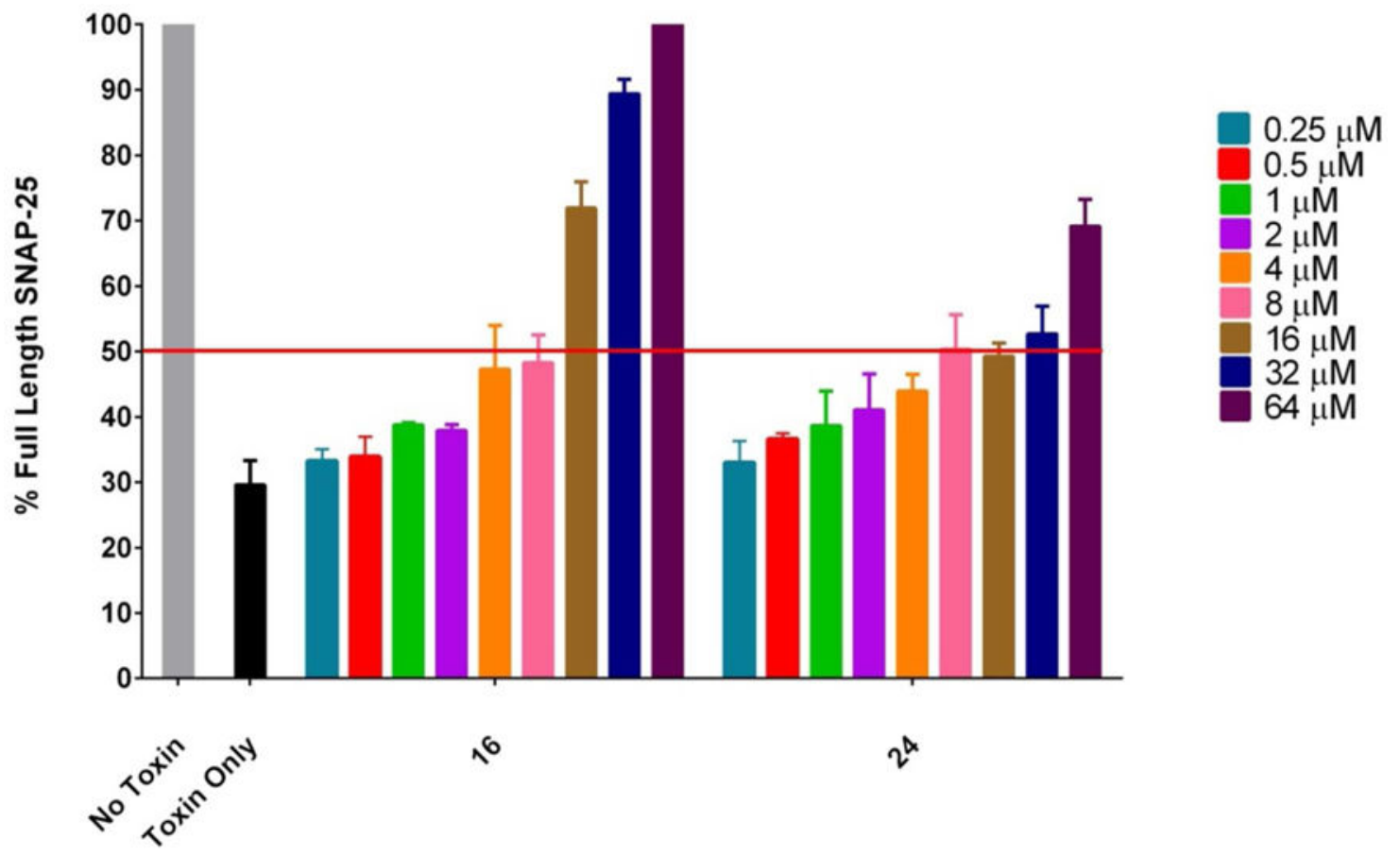

$500 \mathrm{pM}$ BoNT/A

Figure 3.

Protection of SNAP-25 in mES-MNs by compounds $\mathbf{1 6}$ and $\mathbf{2 4}$ administered 30 min postintoxication - dose response experiment 0.25 to $64 \mu \mathrm{M}$ (results are given as mean value of two independent experiments $+/-\mathrm{SEM}$, values given in Table S4). $\mathrm{IC}_{50} \sim 8 \mu \mathrm{M}$. Compound 16 showed potential toxicity at $64 \mu \mathrm{M}$, since GAPDH (used as loading control) levels were lower. In the independent dose-response experiment, $\mathbf{1 6}$ showed protection of SNAP-25 up to $64 \%$ at $20 \mu \mathrm{M}$ (Figure S2, values given in Table S6). 


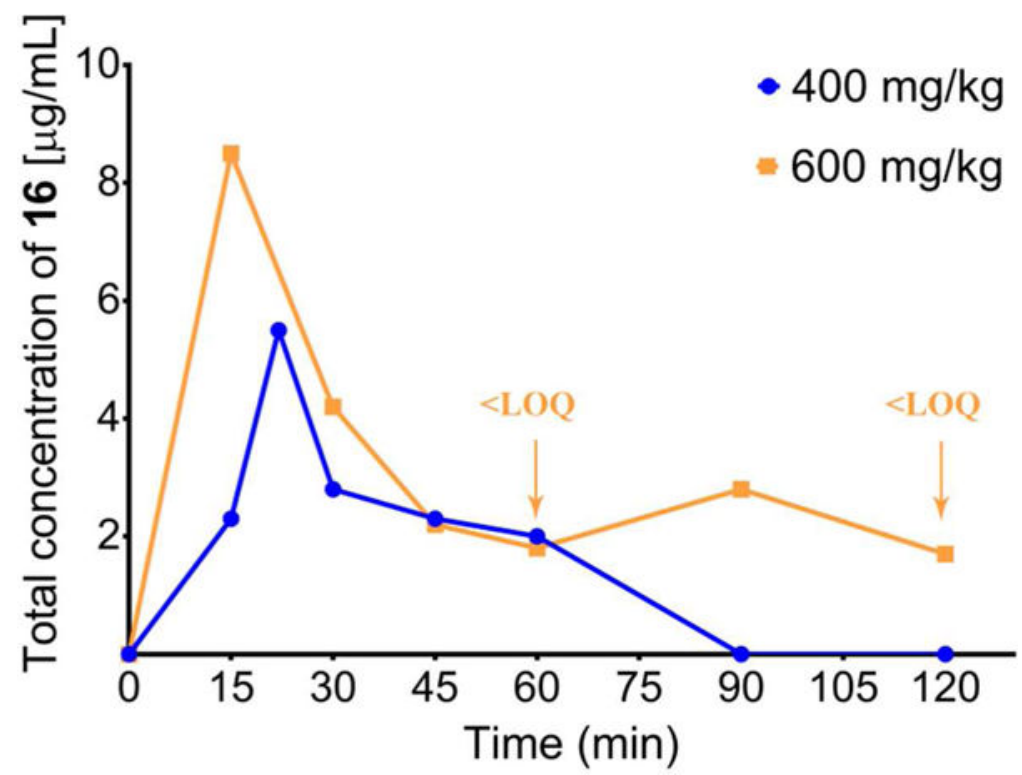

Figure 4.

Pharmacokinetics of $\mathbf{1 6}$ in mice serum after oral dosing at two concentrations -400 and 600 $\mathrm{mg} / \mathrm{kg}$. 


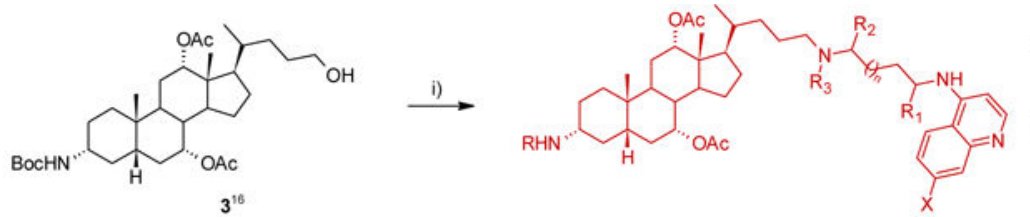

ii) 4: $n=1, R=B o c, R_{1}, R_{2}, R_{3}, X=H(60 \%)$ -12: $n=1, R=B o c, R_{1}, R_{2}, X=H, R_{3}=M e(87 \%)$ 5: $n=1, R=B o c, R_{1}, R_{2}, R_{3}=H, X=C l(66 \%)$ 6: $n=1, R=B o c, R_{1}=M e, R_{2}, R_{3}, X=H(59 \%)$ $\rightarrow 13: n=1, R=B o c, R_{1}, R_{3}=M e, R_{2}, X=H(82 \%)$ 7: $n=1, R=B o c, R_{1}, R_{3}, X=H, R_{2}=M e(65 \%)$ 8: $n=1, R=B o c, R_{1}=M e, R_{2}, R_{3}=H, X=C l(67 \%)$ 9: $n=1, R=B o c, R_{1}, R_{3}=H, R_{2}=\mathrm{Me}, X=C l(77 \%)$

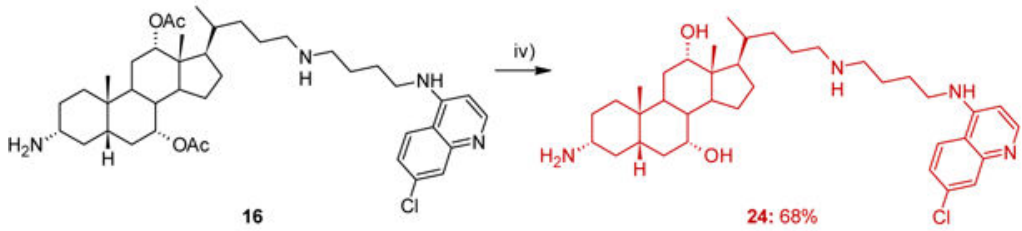
10: $n=3, R=B o c, R_{1}, R_{2}, R_{3}, X=H(54 \%)$ 11: $n=3, R=B$ oc, $R_{1}, R_{2}, R_{3}=H, X=C l(58 \%)$

14: $n=1, R, R_{1}, R_{2}, R_{3}, X=H(48 \%)$

15: $n=1, R, R_{1}, R_{2}, X=H, R_{3}=M e(56 \%)$ 16: $n=1, R, R_{1}, R_{2}, R_{3}=H, X=C l(97 \%)$

17: $n=1, R_{1}=M e, R, R_{2}=H, R_{3}, X=H(71 \%)$ 18: $n=1, R, R_{2}, X=H, R_{1}, R_{3}=M e(60 \%)$ 19: $n=1, R, R_{1}, R_{3}, X=H, R_{2}=M e(94 \%)$ 20: $n=1, R, R_{2}, R_{3}=H, R_{1}=\mathrm{Me}, X=\mathrm{Cl}(97 \%)$ 21: $n=1, R_{,}, R_{1}, R_{3}=H, R_{2}=\mathrm{Me}, X=\mathrm{Cl}(72 \%)$

22: $n=3, R, R_{1}, R_{2}, R_{3}, X=H(76 \%)$

i) 1) $\mathrm{PCC}, \mathrm{CH}_{2} \mathrm{Cl}_{2}$; 2) aminoquinoline, $\mathrm{MeOH}, \mathrm{NaBH}_{4}$; ii) $\mathrm{HCHO}, \mathrm{MeOH}, \mathrm{ZnCl}_{2}, \mathrm{NaBH}_{3} \mathrm{CN}$; iii) $\mathrm{CF}_{3} \mathrm{COOH}, \mathrm{CH}_{2} \mathrm{Cl}_{2}$; 23: $n=3, R_{1}, R_{2}, R_{3}=\mathrm{H}, X=\mathrm{Cl}(92 \%)$

Scheme 1.

Synthesis of novel steroidal derivatives 14-24 


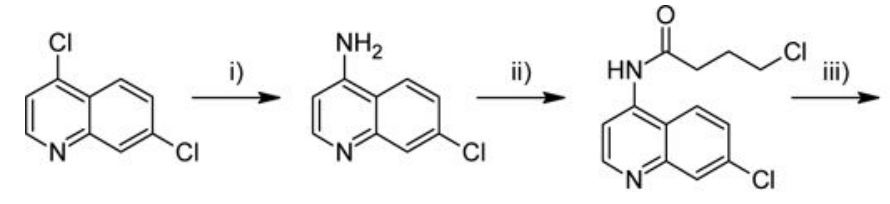

25: $80 \%$

26: $89 \%$

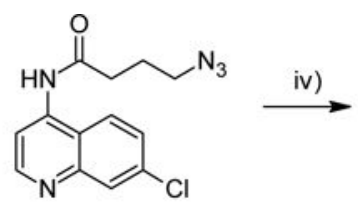

27: $75 \%$

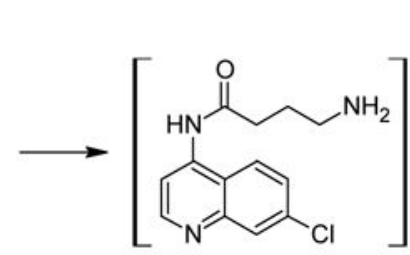

28: $66 \%$

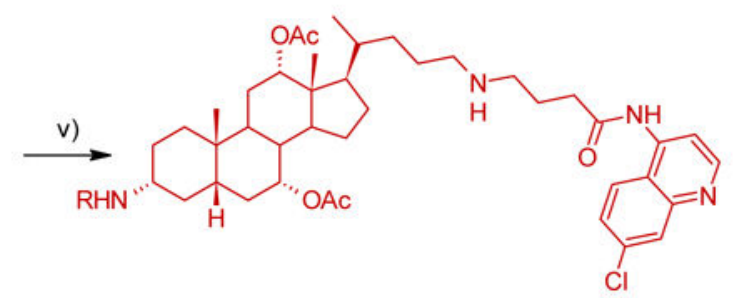

29: $R=B o c(43 \%)$ 30: $\mathrm{R}=\mathrm{H}(80 \%)$ i) $\left(\mathrm{NH}_{4}\right)_{2} \mathrm{CO}_{3}$, phenol, 110 to $165^{\circ} \mathrm{C}, 3.5 \mathrm{~h}$; ii) 4-chlorobutanoyl chloride, $\mathrm{Et}_{3} \mathrm{~N}, \mathrm{CH}_{2} \mathrm{Cl}_{2}, 0^{\circ} \mathrm{C}$ to r.t.; iii) $\mathrm{NaN}_{3}$,
DMF, $80^{\circ} \mathrm{C}$; iv) $\mathrm{Ph}_{3} \mathrm{P}$, THF, $\mathrm{H}_{2} \mathrm{O}, 65^{\circ} \mathrm{C}$; v) 1) aldehyde, dry $\left.\mathrm{MeOH}, 2\right) \mathrm{NaBH}_{4}$; vi) $\mathrm{CF}_{3} \mathrm{COOH}, \mathrm{CH}_{2} \mathrm{Cl}_{2}$

Scheme 2.

Synthesis of steroidal derivative $\mathbf{3 0}$ 


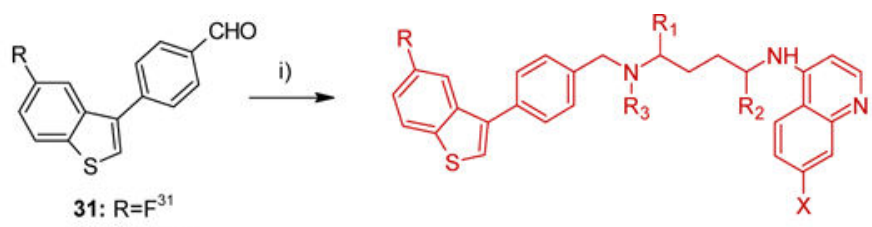

32: $\mathrm{R}=\mathrm{CN}^{31}$

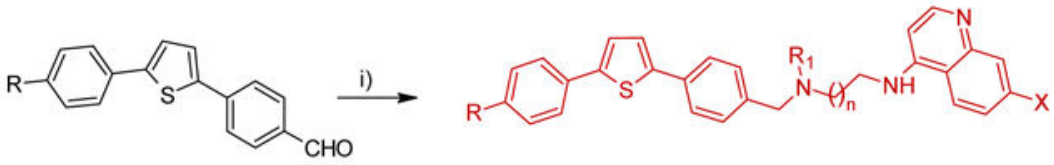

39: $\mathrm{R}=\mathrm{CN}^{31}$

40: $\mathrm{R}=\mathrm{CH}_{2} \mathrm{CN}$

41: $\mathrm{R}=\mathrm{C} \equiv \mathrm{CTMS}^{31}$

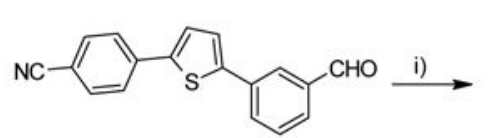

49

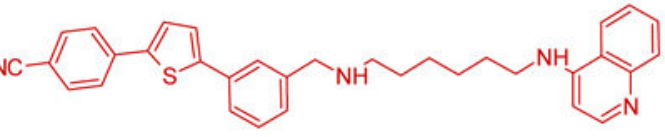

33: $R=F, R_{1}, R_{2}, R_{3}=H, X=C l(56 \%)$

34: $R=F, R_{1}=M e, R_{2}, R_{3}=H, X=H(77 \%)$

35: $R=F, R_{1}, R_{2}, R_{3}=H, X=H(50 \%)^{33}$

37: $\mathrm{R}=\mathrm{F}, \mathrm{R}_{1}, \mathrm{R}_{2}=\mathrm{H}, \mathrm{R}_{3}=\mathrm{Me}, \mathrm{X}=\mathrm{H}(74 \%)$

36: $\mathrm{R}=\mathrm{CN}, \mathrm{R}_{1}, \mathrm{R}_{3}=\mathrm{H}, \mathrm{R}_{2}=\mathrm{Me}, \mathrm{X}=\mathrm{H}(21 \%)^{31}-$

38: $\mathrm{R}=\mathrm{CN}, \mathrm{R}_{1}=\mathrm{H}, \mathrm{R}_{2}, \mathrm{R}_{3}=\mathrm{Me}, \mathrm{X}=\mathrm{H}(74 \%)$

50: $(54 \%)$

i) 1) aminoquinoline/aldehyde, $\mathrm{AcOH}$ glac, $\mathrm{MeOH} / \mathrm{CH}_{2} \mathrm{Cl}_{2}, \mathrm{rt}, 2 \mathrm{~h}$ 2) $\mathrm{NaBH}_{4}, \mathrm{rt}, 12 \mathrm{~h}$; ii) $\mathrm{HCHO}, \mathrm{MeOH}, \mathrm{ZnCl}_{2}, \mathrm{NaBH} \mathrm{CN}$; iii) $\mathrm{K}_{2} \mathrm{CO}_{3}, \mathrm{MeOH}, \mathrm{rt}$

Scheme 3.

Synthesis of novel benzothiophene $(33,34,37,38)$ and thiophene $(42-44,47,48,50)$ derivatives 


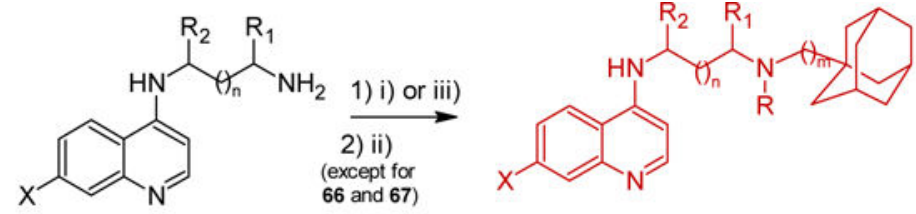

51: $n=0, R_{1}, R_{2}=H, X=C l^{13}$

52: $n=1, R_{1}, R_{2}=H, X=C l^{13}$

53: $n=2, R_{1}, R_{2}=H, X=C l^{13}$

54: $n=0, R_{2}=M e, R_{1}=H, X=C l^{32}$

55: $n=1, \mathrm{R}_{2}=\mathrm{Me}, \mathrm{R}_{1}=\mathrm{H}, \mathrm{X}=\mathrm{Cl}^{32}$

AQ11: $n=0, R_{1}, R_{2}=H, X=H^{34}$

AQ7: $n=1, R_{1}, R_{2}=H, X=H^{32}$

AQ8: $n=2, R_{1}, R_{2}=H, X=H^{32}$
56: $n=0, m=1, R=M e, R_{1}, R_{2}=H, X=C l(82 \%)$

57: $n=1, m=1, R=M e, R_{1}, R_{2}=H, X=C l(87 \%)$

58: $n=2, m=1, R=M e, R_{1}, R_{2}=H, X=C l(93 \%)$

59: $n=0, m=1, R, R_{2}=M e, R_{1}=H, X=C l(91 \%)$

60: $n=1, m=1, R, R_{2}=M e, R_{1}=H, X=C l(87 \%)$

61: $n=0, m=2, R=M e, R_{1}, R_{2}=H, X=C l(89 \%)$

62: $n=1, m=2, R=M e, R_{1}, R_{2}=H, X=C l(84 \%)$

63: $n=2, m=2, R=M e, R_{1}, R_{2}=H, X=C l(86 \%)$

64: $n=0, m=2, R, R_{2}=M e, R_{1}=H, X=C l(93 \%)$

65: $n=1, m=2, R, R_{2}=M e, R_{1}=H, X=C l(80 \%)$

66: $n=1, m=1, R, R_{1}, R_{2}, X=H(60 \%)$

67: $n=1, m=2, R, R_{1}, R_{2}, X=H(70 \%)$

68: $n=1, m=1, R=M e, R_{1}, R_{2}, X=H(72 \%)$

69: $n=1, m=2$ R=Me, $R_{1}, R_{2}, X=H(55 \%)$

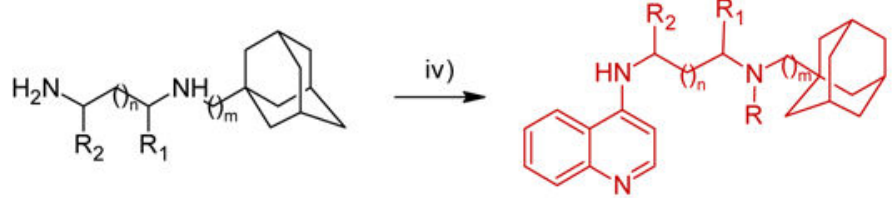

77: $n=0, m=1, R, R_{2}=H, R_{1}=M e(60 \%)$

78: $n=1, m=1, R, R_{2}=H, R_{1}=M e(91 \%)$

84: $\left.n=1, m=1, R, R_{1}=M e, R_{2}=H(89 \%) ~ i i\right)$

79: $n=2, m=1, R, R_{2}=H, R_{1}=M e(44 \%)$

80: $n=0, m=2, R, R_{2}=H, R_{1}=M e(50 \%)$

81: $n=1, m=2, R, R_{2}=H, R_{1}=M e(51 \%)$

82: $n=2, m=2, R, R_{2}=H, R_{1}=M e(53 \%)$

83: $n=1, m=1, R, R_{1}=H, R_{2}=M e(73 \%)^{32} \square$ ii)

72: $n=2, m=1, R_{2}=H, R_{1}=M e^{32}$

73: $n=0, m=2, R_{2}=H, R_{1}=M e^{32}$

74: $n=1, m=2, R_{2}=H, R_{1}=M e^{32}$

75: $n=2, m=2, R_{2}=H, R_{1}=M e^{32}$

76: $n=1, m=1, R_{2}=M e, R_{1}=H^{32}$

i) 1) aminoquinoline/aldehyde, $\mathrm{AcOH}$ glac, $\mathrm{MeOH} / \mathrm{CH}_{2} \mathrm{Cl}_{2}, \mathrm{rt}, 2 \mathrm{~h}$ 2) $\mathrm{NaBH}_{4}, \mathrm{rt}, 12 \mathrm{~h}$; ii) $\mathrm{HCHO}, \mathrm{MeOH}, \mathrm{ZnCl}, \mathrm{NaBH}{ }_{3} \mathrm{CN}$; iii) aldehyde, $\mathrm{NaBH}(\mathrm{OAc})_{3}, \mathrm{CH}_{2} \mathrm{Cl}_{2}, \mathrm{rt}, 24 \mathrm{~h}$; iv) 4-chloroquinoline, $\mathrm{Pd}(\mathrm{OAc})_{2}, \mathrm{SPhos}, \mathrm{K}_{3} \mathrm{PO}_{4}$, dioxane, $85^{\circ} \mathrm{C}, 24 \mathrm{~h}$

\section{Scheme 4.}

Synthesis of novel adamantane derivatives 56-69, 77-82, 84 and 85 

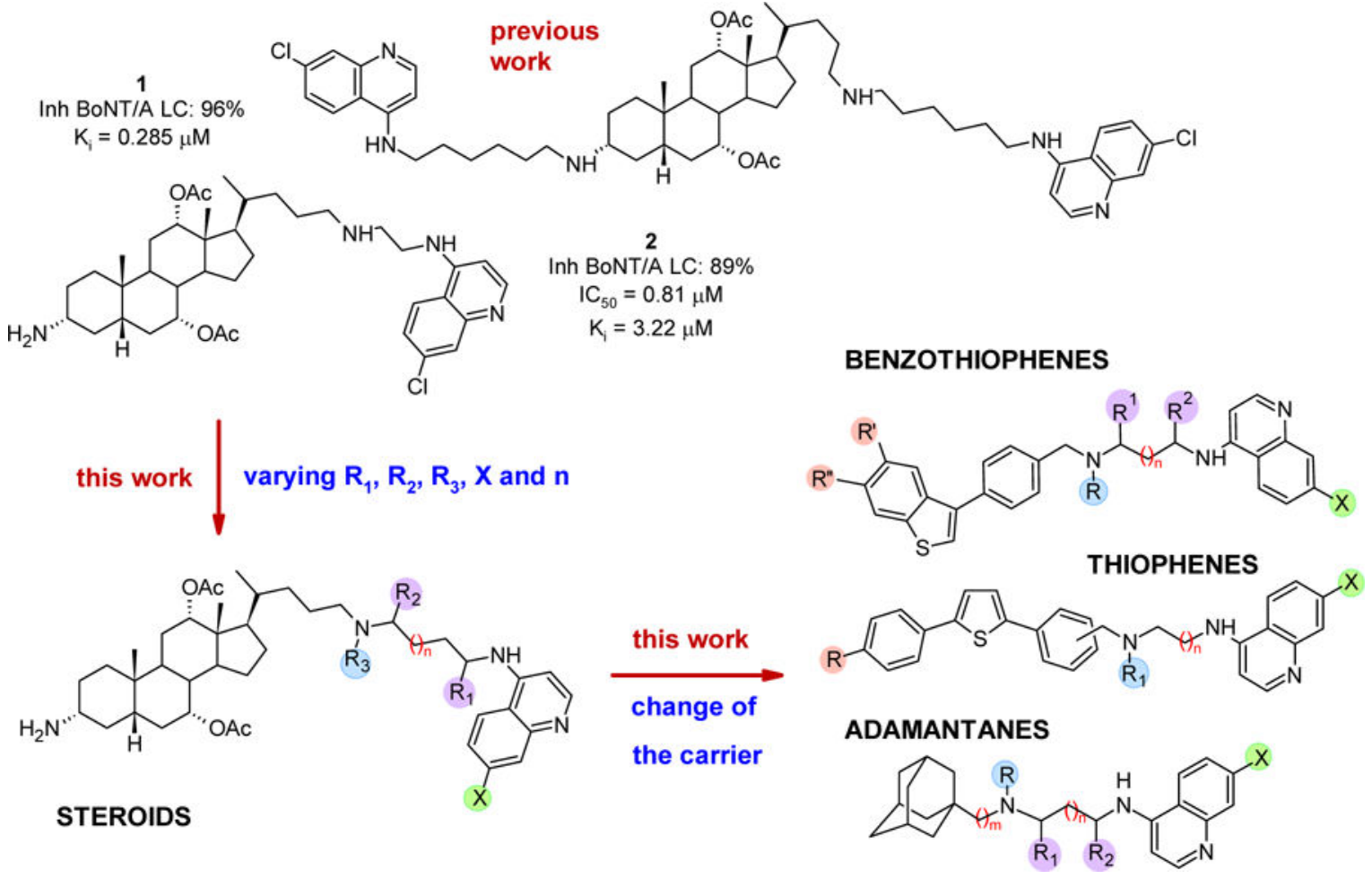

Chart 1.

General structures of investigated steroidal, benzothiophene, thiophene and adamantane derivatives 
Table 1

Inhibitory activities against BoNT/A LC and holotoxin in proteolytic and cell-based assay ${ }^{a}$

\begin{tabular}{|c|c|c|c|c|}
\hline Compound $b$ & $\exp \log D^{c}$ & $\begin{array}{c}\text { In vitro proteolytic assay } \\
\% \text { inh BoNT/A LC at } 20 \\
\mu \mathrm{M} ; \mathrm{IC}_{50}(\mu \mathrm{M})\end{array}$ & $\begin{array}{l}\text { mES-MNs pre intoxication } \\
\% \text { of full length SNAP-25 } \\
\qquad(10 \mu \mathrm{M} ; 20 \mu \mathrm{M})\end{array}$ & $\begin{array}{l}\text { mES-MNs post intoxication } \\
\text { at } 20 \mu M \% \text { of full length } \\
\text { SNAP-25 (30 min; } 60 \text { min) }\end{array}$ \\
\hline 14 & $2.14(\mathrm{pH}=1)$ & $80 ; 5.7$ & $28 ; 67$ & $48 ; 49$ \\
\hline 15 & $2.11(\mathrm{pH}=1)$ & $52 ; 1.5$ & $70 ; 69$ & - \\
\hline 16 & $\begin{array}{c}2.55(\mathrm{pH}=1) \\
2.07(\mathrm{pH}=7.3)^{d}\end{array}$ & $66 ; 4.5$ & $72 ; 88$ & $64 ; 45$ \\
\hline 17 & $2.28(\mathrm{pH}=1)$ & $71 ; 2.7$ & $67 ; 69$ & $38 ; 22$ \\
\hline 18 & $2.38(\mathrm{pH}=1)$ & $85 ; 0.7$ & $20 ; 41$ & - \\
\hline 19 & $2.21(\mathrm{pH}=1)$ & $75 ; 3.0$ & $86 ; 87$ & $50 ; 22$ \\
\hline 24 & $2.97(\mathrm{pH}=1)$ & 48 & $46 ; 58^{e}$ & $49 ;_{-}^{e}$ \\
\hline 34 & $3.85(\mathrm{pH}=10)$ & $75 ; 7.4$ & $58 ; 68$ & $16 ; 17$ \\
\hline 36 & $3.67(\mathrm{pH}=10)$ & $61 ; 10.2$ & $34 ; 53$ & - \\
\hline 37 & $3.98(\mathrm{pH}=10)$ & 46 & $44 ; 55$ & - \\
\hline 38 & $3.42(\mathrm{pH}=10)$ & 27 & $59 ; 64$ & - \\
\hline 86 & $3.67(\mathrm{pH}=10)$ & $84 ; 4.6$ & $21 ; 26$ & - \\
\hline 87 & $3.85(\mathrm{pH}=10)$ & $75 ; 3.3$ & $36 ; 43$ & - \\
\hline 91 & $3.98(\mathrm{pH}=10)$ & $69 ; 8.8$ & $62 ; 62$ & - \\
\hline 46 & $3.08(\mathrm{pH}=1)$ & $70-80 ; 3.4$ & $22 ; 48$ & - \\
\hline 50 & $3.08(\mathrm{pH}=1)$ & $68 ; 8.7$ & $46 ; 71$ & - \\
\hline 93 & $3.42(\mathrm{pH}=1)$ & $77 ; 6.8$ & $31 ; 70$ & $20 ; 19$ \\
\hline 96 & $3.33(\mathrm{pH}=1)$ & 35 & $54 ; 60$ & $34 ; 22$ \\
\hline 101 & $2.93(\mathrm{pH}=1)$ & $67 ; 9.3$ & $18 ; 39$ & - \\
\hline 57 & $3.24(\mathrm{pH}=10)$ & $71 ; 8.8$ & $51 ; 56$ & $46 ; 39$ \\
\hline 60 & $3.47(\mathrm{pH}=10)$ & $67 ; 11.7$ & $63 ; 72$ & $15 ; 16$ \\
\hline 68 & - & 30 & $30 ; 31$ & - \\
\hline 81 & - & - & $23 ; 24$ & - \\
\hline 85 & - & $51 ; 5.2$ & $47 ; 46$ & - \\
\hline 102 & $3.40(\mathrm{pH}=10)$ & $65 ; 2.7$ & $29 ; 30$ & - \\
\hline 103 & $4.33(\mathrm{pH}=10)$ & 2 & $30 ; 29$ & - \\
\hline 104 & $3.24(\mathrm{pH}=10)$ & 15 & $31 ; 35$ & - \\
\hline 105 & $3.09(\mathrm{pH}=10)$ & - & $24 ; 23$ & - \\
\hline 106 & $4.13(\mathrm{pH}=10)$ & - & $30 ; 32$ & - \\
\hline Negative control DMSO & - & - & 100 & 100 \\
\hline Positive control 1 & - & $90 ; 12.4^{f}$ & $70 ; 84$ & $36 ; 20$ \\
\hline
\end{tabular}

${ }^{a}$ Results are given as mean value of three independent experiments.

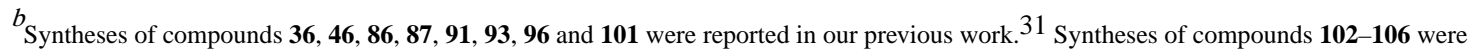
reported in our previous work. ${ }^{32}$ 
${ }^{c}$ Experimental $\log D$ using reversed phase thin-layer chromatography at $\mathrm{pH}=1(\mathrm{MeOH} / \mathrm{HCl}(70 / 30))$ or $\mathrm{pH}=10\left(\right.$ acetone/ $\left.\mathrm{NH}_{3} / \mathrm{H}_{2} \mathrm{O}(85 / 5 / 10)\right)$.

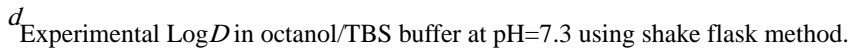

${ }^{e}$ Compound 24 was tested at 8 and $16 \mu \mathrm{M}$ in pre-intoxication model and at $16 \mu \mathrm{M}$ in 30 minutes post-intoxication model only;

$f_{\text {In previous test the inhibition was } 95.46 \% \text { and } K_{\mathrm{i}}=0.285 \mathrm{OM} .}{ }^{16}$ 


\section{Table 2}

Toxicity study in mice ${ }^{a}$

\begin{tabular}{cc}
\hline $\begin{array}{c}\text { Compound } \\
\text { (at } 3 \times \mathbf{1 6 0} \mathbf{~ m g} / \mathbf{k g} \text { dose })\end{array}$ & Mice alive/Total mice \\
\hline $\mathbf{1 6}$ & $5 / 5$ \\
$\mathbf{1 9}$ & $3 / 5$ \\
$\mathbf{3 4}$ & $5 / 5$ \\
$\mathbf{5 7}$ & $4 / 5$ \\
$\mathbf{6 0}$ & $3 / 5$ \\
$\mathbf{9 3}$ & $5 / 5$ \\
$\mathbf{9 6}$ & $5 / 5$ \\
\hline
\end{tabular}

${ }^{a}$ Groups of five healthy mice were treated per os (p.o.) for three consecutive days with aminoquinolines suspended in $0.5 \%$ hydroxyethylcellulose $-0.1 \%$ Tween 80 . Individual mouse behavior and appearance was monitored two times a day for 30 days. 


\section{Table 3}

ADMET parameters for compound $\mathbf{1 6}^{40}$

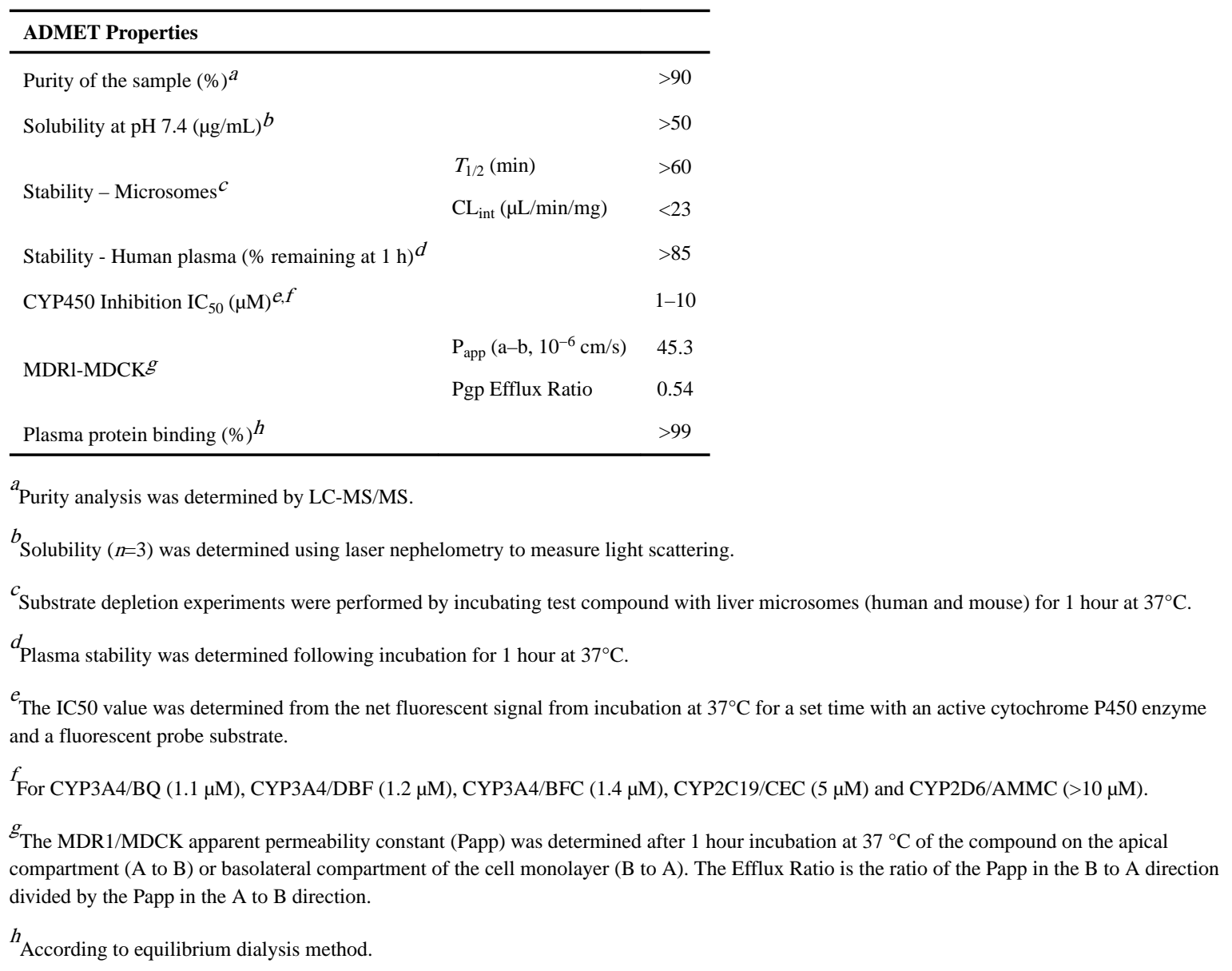


Table 4

Concentration levels of $\mathbf{1 6}$ in mouse serum at different time points following oral administration at two different doses. ${ }^{a}$

\begin{tabular}{ccc}
\hline Time $(\mathbf{m i n})$ & $\mathbf{4 0 0} \mathbf{~ m g} / \mathbf{k g ~ d o s e ~} \boldsymbol{\mu g} / \mathbf{m L}(\boldsymbol{\mu M})$ & $\mathbf{6 0 0} \mathbf{~ m g} / \mathbf{k g ~ d o s e ~} \boldsymbol{\mu g} / \mathbf{m L}(\boldsymbol{\mu M})$ \\
\hline 15 & $2.3(3.3)$ & $\mathbf{8 . 5}(11.9)$ \\
22 & $\mathbf{5 . 5}(\mathbf{7 . 8})$ & $-b$ \\
30 & $2.8(4.0)$ & $4.2(5.9)$ \\
45 & $2.3(3.3)$ & $2.2(3.1)$ \\
60 & $2.0(2.8)$ & $<\mathrm{LOQ}^{c}$ \\
90 & $<\mathrm{LOD}$ & $2.8(4.0)$ \\
120 & $<\mathrm{LOD}$ & $<\mathrm{LOQ}^{d}$ \\
\hline
\end{tabular}

${ }^{a}$ Concentration $\mu \mathrm{g} / \mathrm{mL}$ of compound was determined by UPLC-MS/MS. Concentration in $\mu \mathrm{M}$ is given in parentheses. Results are given as a single value for one mouse for each time point. $\mathrm{LOD}=$ limit of detection; $\mathrm{LOQ}=$ Limit of quantitation.

$b_{\text {Sample was not taken. }}$

${ }^{c}$ Concentration was estimated to $1.8 \mu \mathrm{g} / \mathrm{mL}(2.5 \mu \mathrm{M})<\mathrm{LOQ}$.

${ }^{d}$ Concentration was estimated to $1.7 \mu \mathrm{g} / \mathrm{mL}(2.4 \mu \mathrm{M})<\mathrm{LOQ}$. 
Table 5

In vivo pharmacokinetic properties for $\mathbf{1 6}$ in mice after oral administration at two different concentrations

\begin{tabular}{|c|c|c|}
\hline parameter & $400 \mathrm{mg} / \mathrm{kg}$ dose & $600 \mathrm{mg} / \mathrm{kg}$ dose \\
\hline$T_{\max }(\min )$ & 22 & 15 \\
\hline$C_{\max }(\mu \mathrm{M})$ & 7.8 & 11.9 \\
\hline $\mathrm{AUC}_{0-120}(\mu \mathrm{M}-\mathrm{min})$ & 253 & 526 \\
\hline$t_{1 / 2}(\min )^{a}$ & 43 & 23 \\
\hline time $T_{\mathrm{c}}>3 \mu \mathrm{M}(\mathrm{min})$ & $>45$ & $>45$ \\
\hline Plasma protein binding $(\%) b$ & $>99 \%$ & $>99 \%$ \\
\hline
\end{tabular}

